\title{
Predicting Human Clearance of Organic Anion Transporting Polypeptide Substrates Using Cynomolgus Monkey: In Vitro-In Vivo Scaling of Hepatic Uptake Clearance ${ }^{\S}$
}

\author{
Tom De Bruyn, ${ }^{1}$ Ayşe Ufuk, Carina Cantrill, ${ }^{2}$ Rachel E. Kosa, Yi-an Bi, Mark Niosi, Sweta Modi, \\ A. David Rodrigues, Larry M. Tremaine, Manthena V. S. Varma, Aleksandra Galetin, \\ and J. Brian Houston
}

Centre for Applied Pharmacokinetic Research, Division of Pharmacy and Optometry, School of Medicine, Biology and Health Sciences, University of Manchester, Manchester, United Kingdom (T.D.B., A.U., C.C., A.G., J.B.H.) and Pharmacokinetics, Dynamics and Drug Metabolism (R.E.K., Y.B., M.N., A.D.R., L.M.T., M.V.S.V) and Research Formulations, Pharmaceutical Sciences, (S.M.) Medicines Design, Pfizer, Inc., Groton, Connecticut

Received March 8, 2018; accepted April 26, 2018

\section{ABSTRACT}

This work explores the utility of the cynomolgus monkey as a preclinical model to predict hepatic uptake clearance mediated by organic anion transporting polypeptide (OATP) transporters. Nine OATP substrates (rosuvastatin, pravastatin, repaglinide, fexofenadine, cerivastatin, telmisartan, pitavastatin, bosentan, and valsartan) were investigated in plated cynomolgus monkey and human hepatocytes. Total uptake clearance and passive diffusion were measured in vitro from initial rates in the absence and presence of the OATP inhibitor rifamycin SV, respectively. Total uptake clearance values in plated hepatocytes ranged over three orders of magnitude in both species, with a similar rank order and good agreement in the relative contribution of active transport to total uptake between cynomolgus monkey and human. In vivo hepatic clearance for these nine drugs was determined in cynomolgus monkey after intravenous dosing.
Hepatic clearances showed a range similar to human parameters and good predictions from respective hepatocyte parameters (with 2.7- and 3.8-fold bias on average, respectively). The use of cross-species empirical scaling factors (determined from cynomolgus monkey data either as the data set average or individual drug values) improved prediction (less bias, better concordance) of human hepatic clearance from human hepatocyte data alone. In vitro intracellular binding in hepatocytes also correlated well between species. It is concluded that the minimal species differences observed for the current data set between cynomolgus monkey and human hepatocyte uptake, both in vitro and in vivo, support future use of this preclinical model to delineate drug hepatic uptake and enable prediction of human in vivo intrinsic hepatic clearance.

\section{Introduction}

It is widely accepted that transporters play an important role in the absorption, distribution, and elimination of many drugs, and this is supported by marked pharmacokinetic changes associated with genetic mutations and drug-drug interactions (DDIs) (Giacomini et al., 2010, 2013). However, investigations focusing on quantitative prediction of transporter-mediated clearance including DDIs are still limited (Gertz

This work was supported by a consortium of pharmaceutical companies (GlaxoSmithKline, Lilly, and Pfizer) within the Centre for Applied Pharmacokinetic Research at the University of Manchester.

${ }^{1}$ Current affiliation: Department of Drug Metabolism and Pharmacokinetics, Genentech Inc., South San Franscisco, CA

${ }^{2}$ Current affiliation: Drug Disposition and Safety, Pharmaceutical Sciences, F. Hoffman La Roche, Basel, Switzerland

https://doi.org/10.1124/dmd.118.081315.

S This article has supplemental material available at dmd.aspetjournals.org. et al., 2013; Zamek-Gliszczynski et al., 2013), and confidence in the prediction is low (Jones et al., 2015). The current challenge is to obtain high-quality in vitro and in vivo data from a preclinical species which allow the development and evaluation of robust strategies for extrapolation of in vitro data for the prediction of in vivo behavior. Together with physiologically based pharmacokinetic modeling, the in vitro-derived information can be informative in predicting and assessing the impact of transporters on absorption, distribution and excretion processes and DDIs (Gertz et al., 2014; Galetin et al., 2017).

Various in vitro assays and in vivo animal models have been explored to assess the clinical impact of members of the organic anion transporting polypeptide (OATP) family OATP1B1 and OATP1B3 on the pharmacokinetics of drug candidates (Brouwer et al., 2013; Zamek-Gliszczynski et al., 2013; Feng et al., 2014). However, poor protein homology between transporters in commonly used preclinical species (e.g., mice, rats, and dogs) and humans often results in differences in substrate specificity, which can complicate the extrapolation of preclinical data to the clinical

ABBREVIATIONS: $\mathrm{ABT}, 1$-aminobenzotriazole; $\mathrm{CL}_{\text {active, }}$ active uptake clearance; $\mathrm{CL}_{h}$, hepatic clearance; $\mathrm{CL}_{\text {int }, \mathrm{h}}$, in vivo hepatic intrinsic clearance;

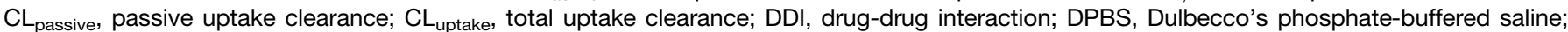
$\mathrm{ESF}$, empirical scaling factor; $\mathrm{ESF}_{\mathrm{av}}$, empirical scaling factor based on average bias of nine drugs; $\mathrm{ESF}_{\text {sd }}$, empirical scaling factor based on individual bias of a specific drug; fu cell, fraction of unbound drug in the cell; gmfe, geometric mean fold error; HPLC, high-performance liquid chromatography; $\mathrm{Kp}_{\text {total }}$, hepatocyte to medium partition coefficient for total drug; $\mathrm{Kp}_{\mathrm{uu}}$, hepatocyte to medium partition coefficient for unbound drug; OATP, organic anion transporting polypeptide; $\mathrm{R}_{\mathrm{b}}$, blood-to-plasma ratio; rmse, root mean squared error. 
setting (Chu et al., 2013a). Recently, it has been reported that transporters in the cynomolgus monkey exhibit a high degree of OATP homology with human isoforms (Ebeling et al., 2011; Shen et al., 2013). For instance, the amino acid sequence identity of cynomolgus monkey OATP1B1, 1B3, and 2B1 has been shown to be approximately $92 \%$, $94 \%$, and $97 \%$ similar, respectively, to their human counterparts (Shen et al., 2013). In the case of protein expression, the levels of OATP1B1, OATP1B3, and OATP2B1 were either 6- to 13-fold greater or 6-fold smaller in cynomolgus monkey liver relative to those in humans, respectively (Wang et al., 2015). In addition, the magnitude of transportermediated DDIs in humans and cynomolgus monkeys appears to be comparable (Shen et al., 2013, 2015; Takahashi et al., 2013) but not always consistent (Chu et al., 2015; Watanabe et al., 2015). Although a comprehensive investigation is still lacking, these studies suggest that the cynomolgus monkey could be a valuable preclinical model to study hepatic uptake of OATP substrates.

Furthermore, the cynomolgus monkey is promising in terms of species similarity in biliary excretion (Kimoto et al., 2017) and endogenous biomarkers (Chu et al., 2015; Thakare et al., 2017); however; intestinal permeability may differ (Takahashi et al., 2009; Miyake et al., 2017). Similarities to humans have been documented in hepatic metabolism specifically for cytochrome P450 enzymes, the latter being important due to the subsequent metabolism of several actively transported drugs and the interplay between these hepatic disposition processes. Eleven members of CYP1A, CYP2A, CYP2C, CYP2D, CYP2E, and CYP3A subfamilies exhibit $>90 \%$ homology in cDNA and amino acid sequences with corresponding human cytochrome P450s (Iwasaki and Uno, 2009). However, expression and activity of CYP3A4/5 in the monkey intestine is particularly high relative to humans, and hence, lower bioavailability was documented relative to humans (Akabane et al., 2010; Nishimuta et al., 2010).

Here, we evaluated the use of the cynomolgus monkey to investigate hepatic uptake mediated by OATP transporters using a judicious selection of nine known OATP substrates (rosuvastatin, pravastatin, repaglinide, fexofenadine, cerivastatin, telmisartan, pitavastatin, bosentan, and valsartan). These drugs represent class $1 \mathrm{~B}$ and $3 \mathrm{~B}$ of the extended clearance classification system where clinical evidence implies that hepatic uptake plays a dominant role in their systemic clearance (Varma et al., $2015,2017)$. A comprehensive in vitro data set of uptake kinetics in hepatocytes was generated with the intent of predicting hepatic clearance in vivo. These predictions were evaluated using experimentally determined in vivo pharmacokinetic data in the cynomolgus monkey. In addition, the in vitro parameters from the cynomolgus monkey were compared with corresponding data from human hepatocytes under identical experimental conditions. Clinical data were also collated from the literature to allow evaluation of the utility of cynomolgus monkey to refine the prediction of in vivo pharmacokinetic behavior in humans. Different approaches to scaling of the in vitro parameters were explored, including the use of empirical scaling factors (ESFs) to minimize the in vitro-in vivo offset. For human prediction, these were derived from the in vitro-in vivo behavior in cynomolgus monkey using either individual clearances for specific drugs or a composite value for the nine drugs. This cross-species strategy has received only limited attention to date, and our findings demonstrate the utility of this methodology for improving predictions of human hepatic clearance for OATPmediated drugs.

\section{Materials and Methods}

In Vitro Studies Using Cryopreserved Hepatocytes. Cryopreserved hepatocytes from humans (HH1025-a 39-year-old female Caucasian) and cynomolgus monkeys (Lot A 10310012 and Lot B 10353012, the latter being a pool of
20 donor livers) were purchased from Life Technologies (Paisley, UK) and In Vitro ADMET Laboratories (Columbia, MD), respectively.

Hepatic uptake of nine OATP substrates (rosuvastatin, pravastatin, repaglinide, fexofenadine, cerivastatin, telmisartan, pitavastatin, bosentan, and valsartan) was investigated in plated hepatocytes 6 hours post seeding. All uptake experiments were conducted as described previously (Ménochet et al., 2012a). In brief, both cynomolgus and human hepatocytes were removed from liquid nitrogen storage and immediately thawed according to the supplier's protocol. Cells were counted under a microscope using a hemocytometer, and the viability was assessed using the trypan blue exclusion method. Only cell suspensions with viability $\geq 85 \%$ were used. Cell suspension was diluted to a density of 750,000 cells $/ \mathrm{ml}$ using the prewarmed InVitroGRO CP (plating) medium (Bioreclamation IVT, Neuss, Germany), and $0.5 \mathrm{ml}$ of cell suspension was added to each well of 24-well collagen I-coated plates (BD Biosciences, Oxford, UK). Cells were incubated for 6 hours at $37^{\circ} \mathrm{C}$ in an atmosphere containing $5 \% \mathrm{CO}_{2}$ to allow adhesion to the collagen. Cell monolayers were visually checked before each experiment.

In cynomolgus monkey hepatocytes, uptake was measured at a single substrate concentration $(1 \mu \mathrm{M})$ for all drugs. After removal of plating medium, cell monolayers were preincubated with Dulbecco's phosphate-buffered saline (DPBS) containing $1 \mathrm{mM} \mathrm{1-aminobenzotriazole} \mathrm{(ABT)} \pm$ OATP inhibitor rifamycin SV $(100 \mu \mathrm{M})$ for 20 minutes. Incubations were initiated by removing the preincubation medium and adding fresh DPBS containing $400 \mu \mathrm{l}$ of substrate \pm rifamycin $\mathrm{SV}$ prewarmed at $37^{\circ} \mathrm{C}$. Total and passive uptake clearance values were measured from initial uptake rates (up to 2 or 5 minutes with 30 -second sampling) in the absence and presence of rifamycin SV, respectively. Hepatic uptake at longer incubation times (up to 45 minutes) in Lot A was used to calculate estimates for the hepatocyte-to-medium concentration ratio $\left(\mathrm{Kp}_{\text {total }}\right)$. $\mathrm{ABT}$ has been documented as not affecting transporter activity in sandwich culture human hepatocytes (Kimoto et al., 2012; Liu and Unadkat, 2013).

For all drugs of interest, human hepatocyte uptake was measured at a single concentration of $1 \mu \mathrm{M}$, with the exception of pravastatin $(10 \mu \mathrm{M})$, fexofenadine $(2 \mu \mathrm{M})$, and valsartan $(2 \mu \mathrm{M})$ due to analytical and slow uptake characteristics. Substrates were dissolved in dimethylsulfoxide and diluted in DPBS [maximum $0.4 \%$ (v/v) dimethylsulfoxide]. Plating medium was removed, and cell monolayers were rinsed twice with prewarmed DPBS and preincubated with fresh DPBS containing $1 \mathrm{mM} \mathrm{ABT} \pm 100 \mu \mathrm{M}$ rifamycin SV for at least 20 minutes. Incubations were started by the addition of $400 \mu \mathrm{l}$ of substrate \pm rifamycin SV prewarmed at $37^{\circ} \mathrm{C}$. After incubation for $30,60,90$, and 120 seconds or 30 , 60,90 , and 300 seconds (pravastatin, fexofenadine, and valsartan) at $37^{\circ} \mathrm{C}$, substrate was collected for analysis. Uptake in human hepatocytes was also assessed at $1 \mu \mathrm{M}$ for all drugs at extended incubation times: up to 45 minutes for repaglinide, 60 minutes for cerivastatin, 120 minutes for fexofenadine and valsartan, and 90 minutes for the remaining drugs. Following substrate removal, the cell monolayers were rinsed three times with $800 \mu \mathrm{l}$ of DPBS, and $200 \mu \mathrm{l}$ of water was added in each well to lyse the cells. Substrate samples and cell lysates were stored at $-20^{\circ} \mathrm{C}$ until analysis. The clearance values were normalized for protein content in the samples, which was measured by the Bicinchoninic Acid protein assay (Pierce Chemical, Rockford, IL).

In each experiment, uptake of $1 \mu \mathrm{M}$ rosuvastatin was measured as a control of the uptake activity. Each time and concentration point was measured in duplicate. The mean uptake of $1 \mu \mathrm{M}$ rosuvastatin control across all cynomolgus monkey experiments performed $(n=5)$ was $40 \pm 9 \mu \mathrm{l} / \mathrm{min} / 10^{6}$ cells, and for human experiments $(n=3)$ was $37 \pm 9 \mu 1 / \mathrm{min} / 10^{6}$ cells. For all other drugs, variation across duplicate measurements were $<10 \%$.

Sample Preparation and Liquid Chromatography-Tandem Mass Spectrometry Analysis of Hepatocyte Samples. All samples were analyzed on an Agilent 1100 high-performance liquid chromatography (HPLC) system (Agilent, Santa Clara, CA) coupled with a Micromass Quattro Ultima triple quadrupole mass spectrometer (Waters, Wilmslow, UK). The analyte and associated internal standard were separated on a Luna C18 column $(5 \mu \mathrm{m}, 50 \times$ $4.6 \mathrm{~mm}$; Phenomenex, Torrance, CA). Varying gradients of four mobile phases were used, the compositions of which were: 1) $90 \%$ water and $0.05 \%$ formic acid with $10 \%$ acetonitrile, 2) $10 \%$ water and $0.05 \%$ formic acid with $90 \%$ methanol, 3) $90 \%$ water and $10 \mathrm{mM}$ ammonium acetate with $10 \%$ methanol, and 4) $10 \%$ water and $10 \mathrm{mM}$ ammonium acetate with $90 \%$ methanol. The flow through the HPLC system was $1 \mathrm{ml} / \mathrm{min}$ and split to $0.25 \mathrm{ml} / \mathrm{min}$ before 
entering the mass spectrometer. All analytes were ionized by positive electrospray. Samples were quantified against a standard curve, and only standards within $30 \%$ of the nominal concentration were included in the standard curve.

Cell lysates and media samples from the uptake experiments were thawed and quenched with an equal volume of methanol containing $1 \mu \mathrm{M}$ internal standard. Samples were placed for at least 1 hour at $-20^{\circ} \mathrm{C}$ before being centrifuged for 10 minutes at $6720 \mathrm{~g}$. All samples were analyzed on an Agilent 1100 HPLC system coupled with a Micromass Quattro Ultima triple quadrupole mass spectrometer. The analyte and associated internal standard were separated on a Luna C18 column $(5 \mu \mathrm{m}, 50 \times 4.6 \mathrm{~mm})$. The flow through the HPLC system was $1 \mathrm{ml} / \mathrm{min}$ and split to $0.25 \mathrm{ml} / \mathrm{min}$ before entering the mass spectrometer. All analytes were ionized by positive electrospray. Samples were quantified against a standard curve, and only standards within $30 \%$ of the nominal concentration were included in the standard curve. In addition, for the repaglinide and telmisartan incubations, the appearance of repaglinide glucuronide and telmisartan glucuronide was monitored.

Determination and Scaling of In Vitro Uptake Kinetic Parameters. Total $\left(\mathrm{CL}_{\text {uptake }}\right)$ and passive $\left(\mathrm{CL}_{\text {passive }}\right)$ uptake clearance values were measured from initial uptake rates in the absence and presence of the OATP inhibitor rifamycin $\mathrm{SV}$, respectively. Uptake rates were calculated over 2 minutes (or 5 minutes for pravastatin and fexofenadine) at $37^{\circ} \mathrm{C}$ from the slope of the linear regression of the cell concentrations versus time plot. Total and passive uptake clearance values were calculated by dividing the slope by the initial substrate concentration and were normalized for protein content. Active uptake clearance $\left(\mathrm{CL}_{\text {active }}\right)$ was calculated by subtracting the $\mathrm{CL}_{\text {passive }}$ from the $\mathrm{CL}_{\text {uptake }}$ (Yabe et al., 2011).

The $\mathrm{Kp}_{\text {total }}$, representing both active uptake and intracellular binding, was calculated from eq. 1 :

$$
\mathrm{Kp}_{\text {total }}=\mathrm{C}_{\text {cell }} / \mathrm{C}_{\text {medium }}
$$

where $\mathrm{C}_{\text {cell }}$ and $\mathrm{C}_{\text {medium }}$ are drug concentrations in the cell and medium, respectively. Cynomolgus hepatocyte volume was set as $3.9 \mu \mathrm{l} / 10^{6}$ cells, assuming the same volume as reported in rat hepatocytes (Reinoso et al., 2001). Human hepatocyte cell volume was $7.6 \mu \mathrm{l} / \mathrm{mg}$ protein ( $\mathrm{Lu}$ et al., 2016), which is equivalent to $7.6 \mu 1 / 10^{6}$ cells (see below).

The hepatocyte to medium partition coefficient for unbound drug $\left(\mathrm{Kp}_{\mathrm{uu}}\right)$ and fraction of unbound drug in the cell $\left(\mathrm{fu}_{\mathrm{cell}}\right)$ were then calculated from eqs. 2 and 3 , respectively (Yabe et al., 2011; Shitara et al., 2013);

$$
\begin{aligned}
\mathrm{Kp}_{\mathrm{uu}} & =\mathrm{CL}_{\text {uptake }} / \mathrm{CL}_{\text {passive }} \\
\mathrm{fu}_{\text {cell }} & =\mathrm{Kp}_{\mathrm{uu}} / \mathrm{Kp}_{\text {total }}
\end{aligned}
$$

When variability in hepatocyte volume was explored (2-8 $\mu 1 / 10^{6}$ cells), the changes in $\mathrm{Kp}_{\text {total }}$ (and hence $\mathrm{fu}_{\text {cell }}$ ) did not change the rank order or incremental differences between compounds.

Human and cynomolgus in vitro intrinsic clearance values expressed as microliters per minute per milligram of protein were converted to microliters per minute/ $10^{6}$ cells by assuming $1 \mathrm{mg}$ of protein is equal to 1 million cells (in-house measurement) and scaled to the in vivo equivalent whole liver by multiplying by hepatocellularity ( $120 \mathrm{M}$ cells/g liver) and average liver weight of 30 and $21.4 \mathrm{~g}$ liver $/ \mathrm{kg}$ body weight in cynomolgus monkeys and humans, respectively (Davies and Morris, 1993; Rawden et al., 2005).

In Vivo Studies. All procedures performed on these animals were in accordance with regulations and established guidelines and were reviewed and approved by an Institutional Animal Care and Use Committee through an ethical review process. Experiments involving male cynomolgus monkeys were conducted at Pfizer (Groton, CT) or Wuxi (WuXi AppTec Co., Ltd., Suzhou, China). Studies at Wuxi were conducted with male cynomolgus macaque Chinese monkeys with bile duct cannulation (cassettes 1 and 2), whereas studies run at Pfizer were conducted with male cynomolgus macaque Mauritian monkeys (cassettes 3 and 4). For each study ( $n=3 /$ study), a cassette of two or three drugs was dosed (cassette $1: 2 \mathrm{mg} / \mathrm{kg}$ pravastatin, $2 \mathrm{mg} / \mathrm{kg}$ rosuvastatin, and $2 \mathrm{mg} / \mathrm{kg}$ valsartan; cassette $2: 1 \mathrm{mg} / \mathrm{kg}$ pitavastatin and $1 \mathrm{mg} / \mathrm{kg}$ fexofenadine; cassette $3: 1 \mathrm{mg} / \mathrm{kg}$ pitavastatin and $1 \mathrm{mg} / \mathrm{kg}$ bosentan; cassette $4: 1 \mathrm{mg} / \mathrm{kg}$ cerivastatin, $1 \mathrm{mg} / \mathrm{kg}$ repaglinide, and $0.5 \mathrm{mg} / \mathrm{kg}$ telmisartan). Doses were selected to minimize interaction between the compounds on the basis of preliminary in vitro uptake studies using monkey hepatocytes (data not shown). Each cassette was administered via intravenous infusion for 30 minutes (cassettes 1 and 2) or a bolus injection (cassettes 3 and 4) via the cephalic vein, in a vehicle of $5 \%$ dimethylsulfoxide $/ 40 \%$ polyethylene glycol $400 \% / 55 \%$ saline (cassette 1 and 2 ), and $10 \%$ ethanol/40\% polyethylene glycol $400 \% / 50 \%$ hydroxyl butyl $\beta$ cyclodextrin (12\% in water) (cassette 4 ). Serial blood samples were collected via the femoral vein before dosing and at predefined time points after that. Blood samples were collected into K2-EDTA-treated collection tubes and were stored on wet ice prior to being centrifuged to obtain plasma. Each plasma sample was added to an equal volume of $0.1 \mathrm{M}$ sodium acetate buffer ( $\mathrm{pH} 4)$ and kept cold during collection, after which the plasma samples were stored frozen at $-70^{\circ} \mathrm{C}$. Urine samples were collected on wet ice and were added to an equal volume of $0.1 \mathrm{M}$ sodium acetate buffer $(\mathrm{pH} 4)$ prior to being stored frozen at $70^{\circ} \mathrm{C}$.

The plasma and urine samples were measured using liquid chromatographytandem mass spectrometry. Standard and quality control samples, prepared in blank plasma or urine with an equal volume of $0.1 \mathrm{M}$ sodium acetate buffer $(\mathrm{pH}$ 4), were extracted in the same manner as the in-life samples. In some cases, urine samples were diluted 10-fold into plasma for bioanalysis. In brief, a Waters ACQUITY ultra performance liquid chromatography system (Waters, Milford, MA) coupled to an API 4000 quadrupole linear ion trap hybrid mass spectrometer equipped with either an atmospheric pressure chemical ionization or electrospray ionization source (depending upon analyte; Applied Biosystems, MDS Sciex, Foster City, CA) was used. Chromatographic separation was accomplished using a Waters Acquity UPLC BEH C18 column $(1.7 \mu \mathrm{m}, 2.1 \times 50 \mathrm{~mm}$; cassette 1$)$, a Waters XSELECT CSH XP C18 column $(2.5 \mu \mathrm{m}, 2.1 \times 50 \mathrm{mM}$; cassette 2$)$, or a Waters XSelect HSS T3 column $(2.5 \mu \mathrm{m}, 2.0 \times 30 \mathrm{~mm}$; cassette 4$)$ maintained at either room temperature or $45^{\circ} \mathrm{C}$. The mobile phase consisted of two solvents. For cassettes 1 and 2, solvent A was $0.025 \%$ formic acid and $1 \mathrm{mM} \mathrm{NH}_{4} \mathrm{OAC}$ in water/acetonitrile $(95: 5, \mathrm{v} / \mathrm{v})$, and solvent B was $0.025 \%$ formic acid and $1 \mathrm{mM}$ $\mathrm{NH}_{4} \mathrm{OAC}$ in water/acetonitrile (5:95, v/v). For cassette 3, solvent A was $0.1 \%$ formic acid in water, and solvent $B$ was acetonitrile. For cassette 4 , solvent A was $0.1 \%$ formic acid in water, and solvent B was acetonitrile. The elution gradient varied slightly by matrix and analyte. The gradient generally began at $3 \%-30 \% \mathrm{~B}$ until about 1.2 minutes, followed by an increase to $50 \%-65 \%$ B to 1.6 minutes, then decreased to $10 \%-30 \%$ B until $\sim 1.7-1.9$ minutes. Standard curves (minimum of six concentrations) and quality control samples (three concentrations prepared in duplicate) were prepared separately in blank plasma and bile and were extracted in the same manner as the in-life samples. Analyst 1.4.2 or 1.6.2 software (SCIEX, Framingham, MA) was used for peak integration and standard curve regression. Watson LIMS version 7.5 (Thermo Fisher Scientific, Waltham, MA) was used for calculation of pharmacokinetic parameters. The percentage of unchanged parent excreted into urine was calculated as follows: urine concentration $(\mathrm{ng} / \mathrm{ml}) \times$ total urine volume $(\mathrm{ml}) /$ total dose $(\mathrm{ng}) \times 100$.

Determination of In Vivo Intrinsic Clearance. In vivo intrinsic hepatic clearance values $\left(\mathrm{CL}_{\text {int,h }}\right)$ for all drugs were determined from systemic clearances obtained following intravenous bolus administration. Hepatic clearance $\left(\mathrm{CL}_{\mathrm{h}}\right)$ was calculated from systemic clearance $\left(\mathrm{CL}_{\text {total }}\right)$ by accounting for renal excretion $\left(\mathrm{CL}_{\mathrm{R}}\right)$ and the blood/plasma concentration ratio $\left(\mathrm{R}_{\mathrm{b}}\right)$ in humans. In vivo $\mathrm{CL}_{\text {int,h }}$ was calculated from $\mathrm{CL}_{\mathrm{h}}$ using the well stirred liver model (Pang and Rowland, 1977) according to eq. 4 :

$$
\mathrm{CL}_{\mathrm{int}, \mathrm{h}}=\frac{\mathrm{CL}_{\mathrm{h}}}{\frac{\mathrm{f}_{\mathrm{u}}}{\mathrm{R}_{\mathrm{b}}} \times\left(1-\frac{\mathrm{CL}_{\mathrm{h}}}{\mathrm{Q}_{\mathrm{h}}}\right)}
$$

where $\mathrm{Q}_{\mathrm{h}}$ represents the blood flow in monkeys $(43.6 \mathrm{ml} / \mathrm{kg}$ ) or humans $(20.7 \mathrm{ml} / \mathrm{kg})$, and $f_{u}$ is the experimentally determined free fraction in plasma in monkeys or humans. $R_{b}$ in cynomolgus monkeys was not available and was assumed to be the same as human $R_{b}$ values.

Prediction of the in vivo intrinsic hepatic clearance was assessed in terms of bias and precision of in vitro values using the absolute geometric mean fold error (gmfe, eq. 5) and the root mean squared error (rmse, eq. 6), respectively (Gertz et al., 2010). Qualitative assessment of predictions were judged as being well predicted when in vitro values fell within 2-fold of the observed in vivo data. Values above or below this threshold were determined to be overpredicted or underpredicted, respectively:

$$
\begin{aligned}
\text { gmfe } & =10 \frac{\sum\left[\log \frac{C L_{\text {int, in viro }}}{\mathrm{CL} L_{\text {int }} \text { in vivo }}\right]}{n} \\
\text { rmse } & =\sqrt{\frac{1}{n} \sum(\text { predicted }- \text { observed })^{2}}
\end{aligned}
$$


Empirical scaling factors were also explored in each species using the bias metric gmfe. In addition, cross-species optimization of human predictions from human hepatocytes was investigated in two ways: 1) by the use of the gmfe from the cynomolgus monkey relationship between in vivo clearance and in vitro predicted clearance for the data set of nine drugs $\left(\mathrm{ESF}_{\mathrm{av}}\right)$, and 2) by using individual drug empirical scaling factors for each specific drug obtained from the ratio of observed to predicted cynomolgus monkey clearance $\left(\mathrm{ESF}_{\mathrm{sd}}\right)$ (Naritomi et al., 2001; Ito and Houston, 2005).

\section{Results}

A linear time-dependent increase in uptake was observed in cynomolgus monkey and human hepatocytes over the initial 2 minutes of the incubation for the nine drugs studied (rosuvastatin, pravastatin, repaglinide, fexofenadine, cerivastatin, telmisartan, pitavastatin, bosentan, and valsartan; see Supplemental Figs. 1 and 2). Inclusion of rifamycin SV provided an estimate of the passive component on the assumption of complete inhibition of transporter proteins in these incubations. The clearance parameters for active, passive, and total uptake, together with $\mathrm{Kp}_{\mathrm{uu}}$, for each drug are shown in Fig. 1 for two cynomolgus monkey lots and are compared with both the human donor reported here and previously reported values from three other human donors using the same methodology (Ménochet et al., 2012b). Metabolism mediated by cytochrome P450 was inhibited by the presence of ABT in each incubation; therefore, for cerivastatin and bosentan in particular, no confounding effects from metabolism were expected. In the case of repaglinide and telmisartan, the glucuronide was only detected in repaglinide incubations in monkey hepatocytes but represented $<12 \%$ of parent drug and was not incorporated into $\mathrm{CL}_{\text {uptake }}$ calculations. In human hepatocytes, previous studies have shown metabolic clearance by conjugation to be $<1 \%$ of uptake clearance (Ménochet et al., 2012b), so no correction was made. Longer incubations (up to 90 minutes) were also carried out to allow attainment of equilibrium between media and cellular drug concentrations to obtain assessment of cellular partitioning and binding (Fig. 2).

Uptake Parameters in Cynomolgus Monkey Hepatocytes. In hepatocyte lot $\mathrm{A}$, a 50-fold range in $\mathrm{CL}_{\text {uptake }}$ was observed (Table 1), with telmisartan showing the highest $\mathrm{CL}_{\text {uptake }}(387 \mu \mathrm{l} / \mathrm{min} / \mathrm{mg}$ protein), and fexofenadine the lowest $\left(\mathrm{CL}_{\text {uptake }} 8 \mu \mathrm{l} / \mathrm{min} / \mathrm{mg}\right.$ protein). $\mathrm{CL}_{\text {active }}$ values showed a larger range of values (180-fold), with similar drugs representing the extreme values. $\mathrm{A}>40$-fold range in $\mathrm{CL}_{\text {passive }}$ was observed, where cerivastatin $(221 \mu \mathrm{l} / \mathrm{min} / \mathrm{mg}$ protein) and pravastatin ( $5 \mu \mathrm{l} / \mathrm{min} / \mathrm{mg}$ protein) showed the highest and the lowest values, respectively. These clearance values resulted in a 7 -fold range in $\mathrm{Kp}_{\mathrm{uu}}$ values among the nine drugs (Fig. 1). The $\mathrm{Kp}_{\mathrm{uu}}$ of rosuvastatin and valsartan was $>5$, whereas pitavastatin and telmisartan showed $\mathrm{Kp}_{\mathrm{uu}}>2$, and the remaining drugs were between 1 and 2 .

Also shown in Fig. 1 are the corresponding parameter values for a second cynomolgus monkey lot (lot B-a pool of 20 donors). Comparison of the $\mathrm{CL}_{\text {uptake, }} \mathrm{CL}_{\text {passive, }}$ and $\mathrm{CL}_{\text {active }}$ values obtained in the hepatocytes from the two lots resulted in an overall good agreement
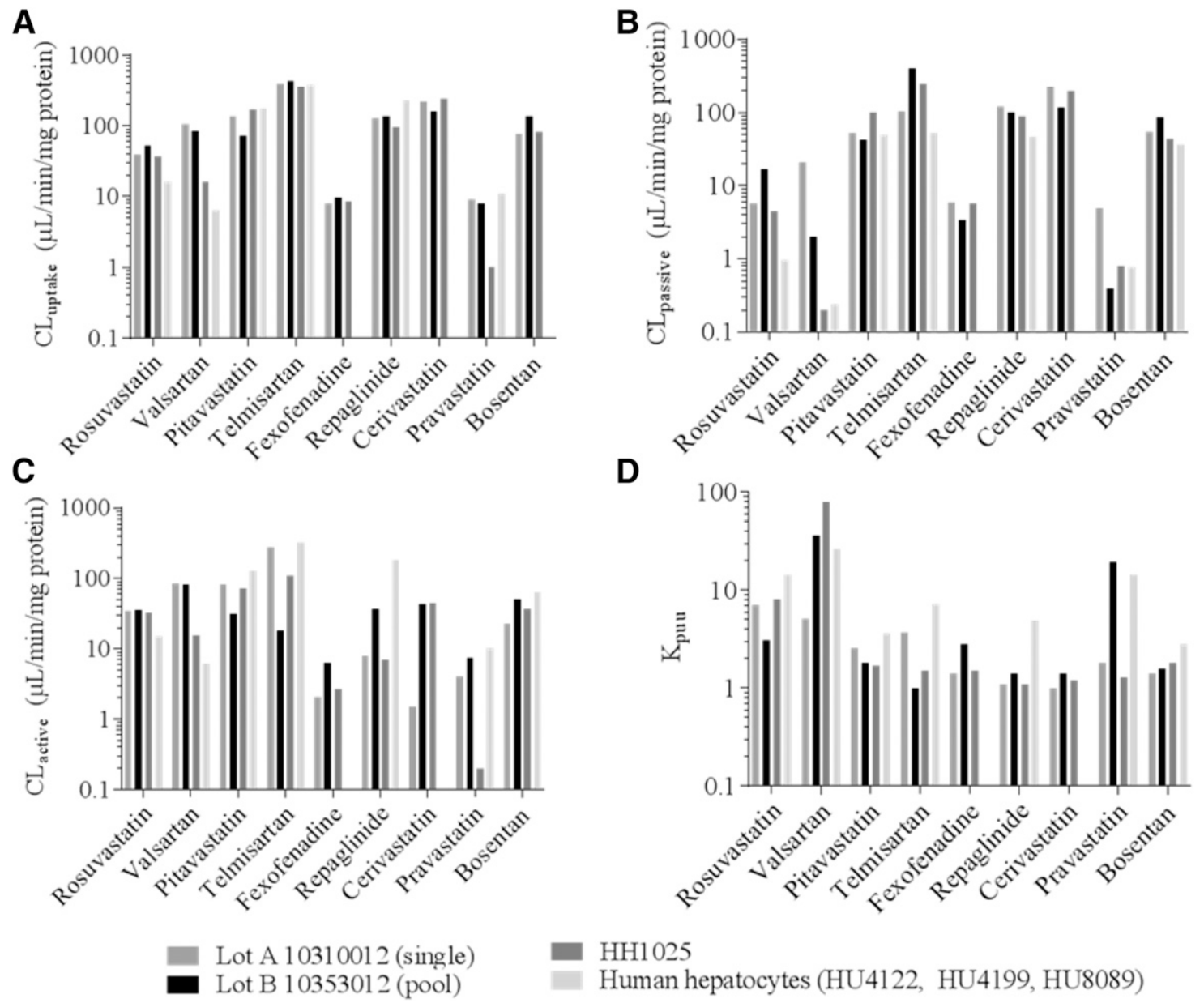

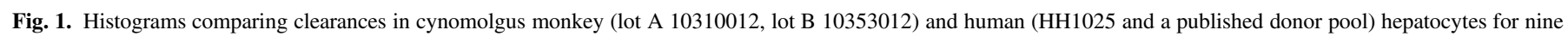
known OATP substrates. For all drugs, variation across duplicate measurements was $<10 \%$. Total uptake (A), passive (B), active clearance (C), and Kpuu (D). 
A

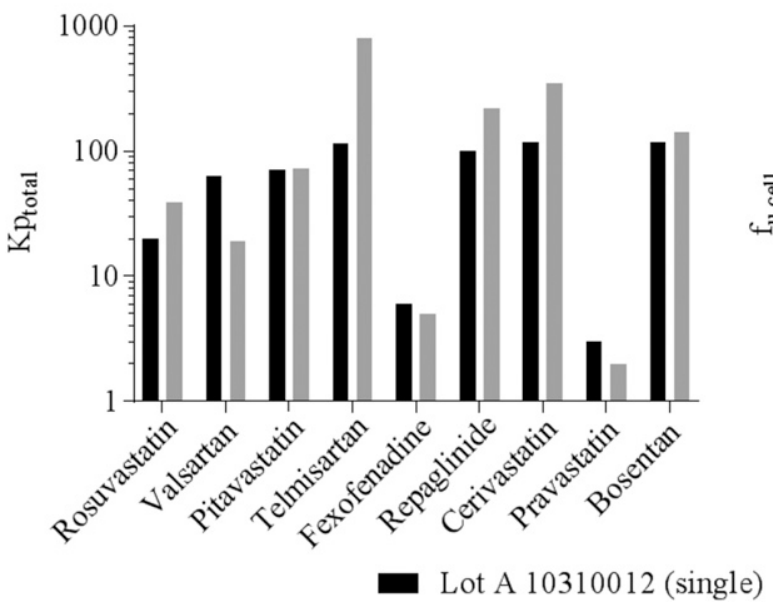

B

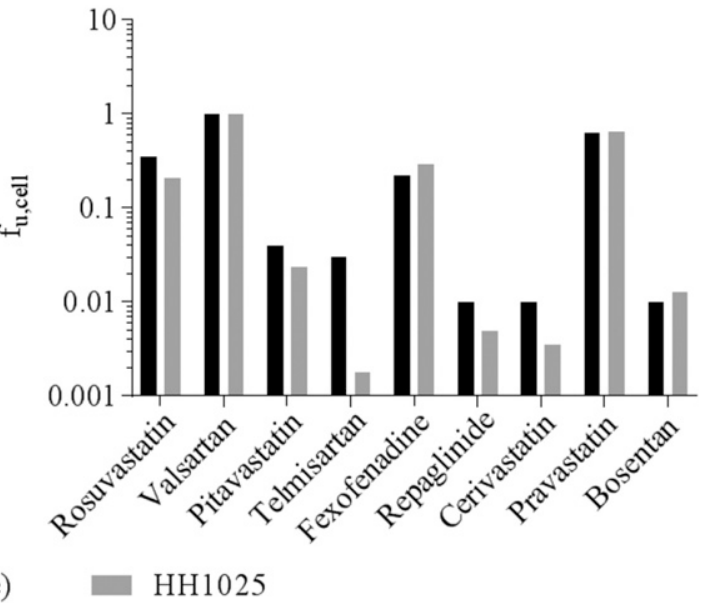

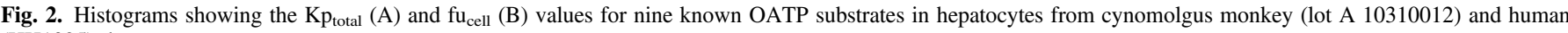
(HH1025) donors.

(Supplemental Fig. 3), with most of the parameter values within 2-fold between individual donors; particularly good agreement was observed with $\mathrm{CL}_{\text {uptake }}$. However, in the $\mathrm{CL}_{\text {active }}$ correlation analysis

TABLE 1

In vitro kinetic parameters for the hepatic uptake of nine OATP substrates in cynomolgus monkey and human hepatocytes

\begin{tabular}{|c|c|c|c|c|}
\hline \multirow{2}{*}{ Donor } & $\mathrm{CL}_{\text {uptake }}$ & $\mathrm{CL}_{\text {passive }}$ & $\mathrm{CL}_{\text {active }}$ & \multirow{2}{*}{$\mathrm{Kp}_{\mathrm{uu}}$} \\
\hline & \multicolumn{3}{|c|}{$\mu \mathrm{l} / \mathrm{min} / \mathrm{mg}$ protein } & \\
\hline \multicolumn{5}{|l|}{ Bosentan } \\
\hline Lot A & 77 & 54 & 23 & 1.4 \\
\hline Lot B & 137 & 86 & 51 & 1.6 \\
\hline HH1025 & 81 & 44 & 37 & 1.8 \\
\hline \multicolumn{5}{|l|}{ Cerivastatin } \\
\hline Lot A & 223 & 221 & 1.5 & 1 \\
\hline Lot B & 161 & 117 & 44 & 1.4 \\
\hline HH1025 & 244 & 199 & 45 & 1.2 \\
\hline \multicolumn{5}{|c|}{ Fexofenadine } \\
\hline Lot A & 8 & 5.9 & 2.1 & 1.4 \\
\hline Lot B & 9.7 & 3.4 & 6.3 & 2.8 \\
\hline HH1025 & 8.4 & 5.7 & 2.7 & 1.5 \\
\hline \multicolumn{5}{|l|}{ Pitavastatin } \\
\hline Lot A & 134 & 52 & 82 & 2.6 \\
\hline Lot B & 73 & 42 & 32 & 1.8 \\
\hline HH1025 & 172 & 100 & 72 & 1.7 \\
\hline \multicolumn{5}{|l|}{ Pravastatin } \\
\hline Lot A & 9 & 5 & 4 & 1.8 \\
\hline Lot B & 7.9 & 0.4 & 7.5 & 19 \\
\hline HH1025 & 1 & 0.8 & 0.2 & 1.3 \\
\hline \multicolumn{5}{|l|}{ Repaglinide } \\
\hline Lot A & 129 & 121 & 8 & 1.1 \\
\hline Lot B & 138 & 101 & 37 & 1.4 \\
\hline HH1025 & 95 & 88 & 7 & 1.1 \\
\hline \multicolumn{5}{|l|}{ Rosuvastatin } \\
\hline Lot A & $40.1 \pm 9$ & $5.7 \pm 2$ & 34.4 & 7.0 \\
\hline Lot B & 53 & 17 & 36 & 3.1 \\
\hline HH1025 & $37 \pm 9$ & $4.8 \pm 0.5$ & 33 & 8.2 \\
\hline \multicolumn{5}{|l|}{ Telmisartan } \\
\hline Lot A & 387 & 104 & 283 & 3.7 \\
\hline Lot B & 425 & 407 & 18 & 1 \\
\hline HH1025 & 351 & 242 & 109 & 1.5 \\
\hline \multicolumn{5}{|l|}{ Valsartan } \\
\hline Lot A & 105 & 21 & 84 & 5.1 \\
\hline Lot B & 85 & 2 & 83 & 37 \\
\hline HH1025 & 15.9 & 0.2 & 15.7 & 80 \\
\hline
\end{tabular}

Lot A and lot B represent a single (10310012) and pooled (10353012) donors of cynomolgus hepatocytes, respectively. The mean uptake of rosuvastatin control across all experiments performed in this study $(n=5)$ for cynomolgus monkeys and $(n=3)$ for humans is shown, and for all other drugs variation across duplicate measurements was $<10 \%$.
(Supplemental Fig. 3B), cerivastatin and telmisartan were clear outliers, as were pravastatin and valsartan in the $\mathrm{CL}_{\text {passive }}$ correlation (Supplemental Fig. 3C). $\mathrm{CL}_{\text {passive }}$ of the nine drugs investigated was strongly correlated with the $\log \mathrm{D}_{7.4}$ (Fig. 3). Consideration of the relationship between $\mathrm{CL}_{\text {passive }}$ and $\log \mathrm{D}_{7.4}$ for both lots provides no further explanation for the pravastatin and valsartan (the most hydrophilic drugs investigated) behavior described earlier.

The $\mathrm{Kp}_{\text {total }}$ values to assess total drug uptake for the nine compounds were obtained from the uptake time profiles over 90 minutes. Most of the drugs investigated reached equilibrium within 30 minutes, with the exceptions of bosentan and valsartan. The $\mathrm{Kp}_{\text {total }}$ parameters obtained are shown in Table 2, and a 50-fold range in $\mathrm{Kp}_{\text {total }}$ values is evident (Fig. 2), with values ranging from 3 (pravastatin) to 141 (bosentan). For six out of nine drugs, the $\mathrm{Kp}_{\text {total }}$ values were $>50$, whereas rosuvastatin, fexofenadine, and pravastatin showed comparably low values.

The intracellular fraction unbound ( $\left(\mathrm{fu}_{\mathrm{cell}}\right)$ was calculated using $\mathrm{Kp}_{\text {total }}$ and $\mathrm{Kp}_{\mathrm{uu}}$ values. There was a large (100-fold) range in fu $\mathrm{cell}_{\text {cll }}$ (Fig. 2); high intracellular binding was observed for bosentan, cerivastatin, pitavastatin, repaglinide, and telmisartan $\left(\mathrm{fu}_{\text {cell }}<0.05\right)$. The derived $\mathrm{fu}_{\text {cell }}$ values for the nine drugs investigated were correlated with the $\log \mathrm{D}_{7.4}$, albeit with less precision for the high binders (Fig. 3).

Uptake Parameters in Human Hepatocytes. The uptake of the selected compounds was assessed in cryopreserved plated human hepatocytes (HH1025) under experimental conditions identical to the cynomolgus monkey hepatocyte studies. Kinetic parameters obtained are summarized in Table 1 and compared with the corresponding cynomolgus monkey parameters in Fig. 4. For all parameters there was a similar range of values obtained across the nine drugs in humans compared with cynomolgus monkeys, although for certain drugs (notably pravastatin and valsartan), human values were less than the cynomolgus monkey.

Pravastatin showed the lowest extent of uptake, with $\mathrm{CL}_{\text {uptake }}$ of $1 \mu \mathrm{l} / \mathrm{min} / \mathrm{mg}$ protein, whereas telmisartan had the highest value (351 $\mu \mathrm{l} / \mathrm{min} / \mathrm{mg}$ protein) (Fig. 1). $\mathrm{CL}_{\text {active }}$ differed by 500 -fold with the same drugs as extremes: pravastatin $(0.2 \mu \mathrm{l} / \mathrm{min} / \mathrm{mg}$ protein $)$ and telmisartan (109 $\mu \mathrm{l} / \mathrm{min} / \mathrm{mg}$ protein). $\mathrm{CL}_{\text {passive }}$ values were comparatively low for the majority of compounds investigated, ranging from 0.2 to $242 \mu \mathrm{l} / \mathrm{min} / \mathrm{mg}$ protein for valsartan and telmisartan, respectively. Human $\mathrm{Kp}_{\mathrm{uu}}$ values were comparable to those presented earlier for the cynomolgus monkey lot A (Fig. 4D).

$\mathrm{Kp}_{\text {total }}$ and, subsequently, fu $\mathrm{fu}_{\text {cell }}$ values were also determined in this human donor (see Table 2). Figure 5 compares these data with the 


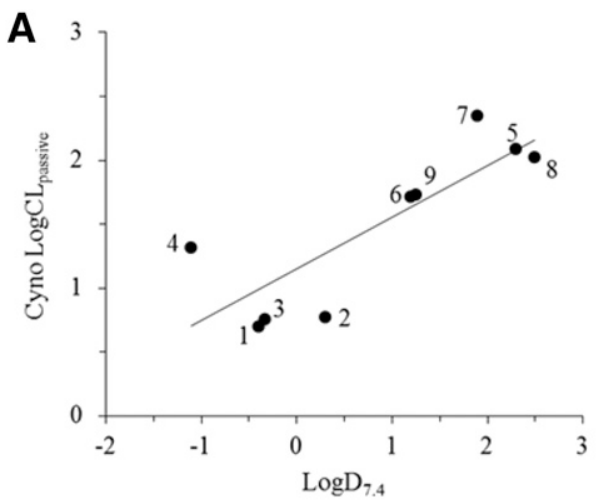

C

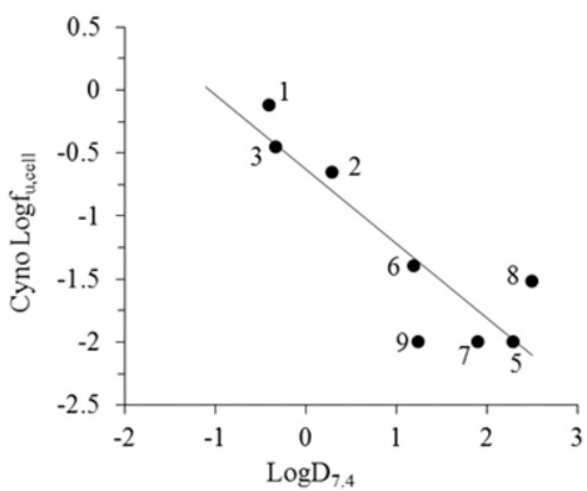

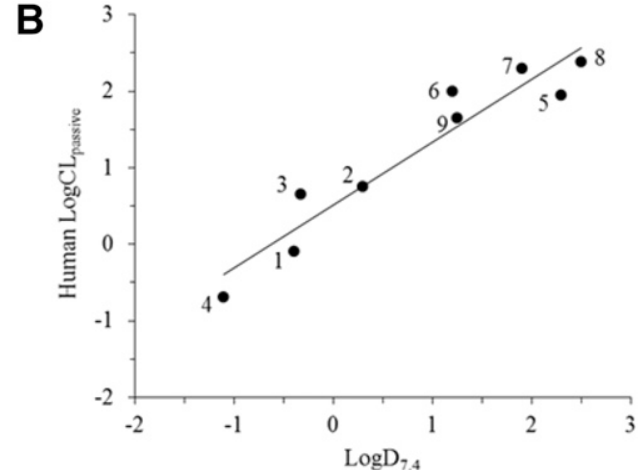

D

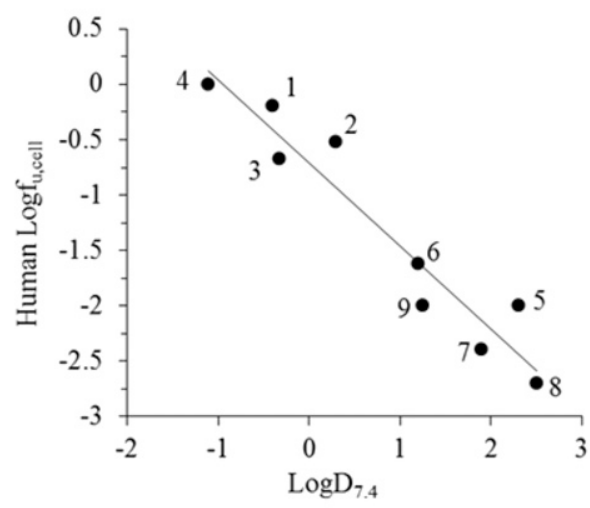

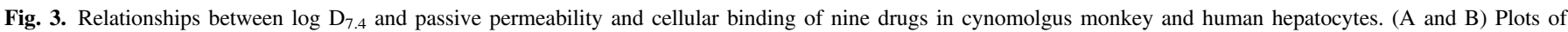

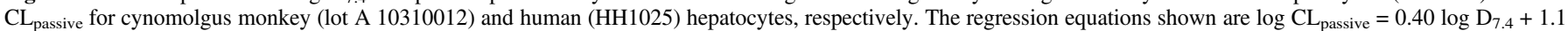

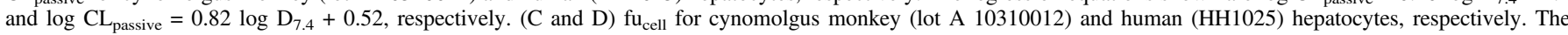

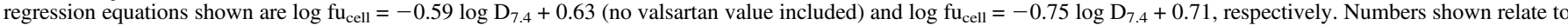
particular drugs: 1, pravastatin; 2, fexofenadine; 3, rosuvastatin; 4, valsartan; 5, repaglinide; 6, pitavastatin; 7, cerivastatin; 8, telmisartan; 9, bosentan.

corresponding cynomolgus monkey parameters and indicates minimal species differences in the cellular binding of these drugs. A similar range of values is evident, as well as an identical rank order with the exception of telmisartan; the human $\mathrm{fu}_{\text {cell }}$ was an order of magnitude lower than in cynomolgus monkey. If the $\log \mathrm{D}_{7.4}$ relationship (Fig. 3) is considered for each species, it can be argued that for the cynomolgus monkey, telmisartan $\mathrm{fu}_{\text {cell }}$ is overestimated. The use of the $\log \mathrm{D}_{7 \cdot 4}$ relationship for the cynomolgus monkey (excluding telmisartan) estimates telmisartan $\mathrm{fu}_{\text {cell }}$ to be 0.007 with a corresponding $\mathrm{Kp}_{\text {total }}$ of 525 and removes the outlying tendency for this drug.

TABLE 2

Hepatocyte-to-medium drug concentration ratios and intracellular fraction of unbound drug for nine OATP substrates in plated cynomolgus and human hepatocytes

\begin{tabular}{|c|c|c|c|c|c|}
\hline \multirow{2}{*}{ Compounds } & \multicolumn{2}{|c|}{ Cynomolgus Monkey } & \multicolumn{2}{|c|}{ Human } & \multirow{2}{*}{$\log D_{7.4}$} \\
\hline & $\mathrm{Kp}_{\text {total }}$ & $\mathrm{fu}_{\text {cell }}$ & $\mathrm{Kp}_{\text {total }}$ & $\mathrm{fu}_{\text {cell }}$ & \\
\hline Bosentan & 141 & 0.01 & 142 & 0.01 & 1.25 \\
\hline Cerivastatin & 118 & 0.01 & 352 & 0.004 & 1.9 \\
\hline Fexofenadine & 6 & 0.22 & 5 & 0.3 & 0.3 \\
\hline Pitavastatin & 71 & 0.04 & 73 & 0.024 & 1.2 \\
\hline Pravastatin & 3 & 0.64 & 2 & 0.64 & -0.4 \\
\hline Repaglinide & 101 & 0.01 & 221 & 0.01 & 2.3 \\
\hline Rosuvastatin & 20 & 0.35 & 39 & 0.21 & -0.33 \\
\hline Telmisartan & 115 & 0.03 & 807 & 0.002 & 2.5 \\
\hline Valsartan & 64 & $1.0^{a}$ & 19 & 1.0 & -1.11 \\
\hline
\end{tabular}

${ }^{a}$ Calculated from the relationship $\log \mathrm{fu}_{\mathrm{cell}}=-0.59 \log \mathrm{D}_{7.4}+0.63$.
Prediction of Cynomolgus Monkey and Human In Vivo Clearance. The pharmacokinetic studies for the nine drugs investigated were conducted following a single intravenous infusion over 30 minutes to three male cynomolgus monkeys. The in vivo parameters obtained are shown in Table 3, and plasma concentration-time profiles are shown in Supplemental Fig. 4. The $\mathrm{CL}_{\text {total }}$ values ranged from 6.5 (for valsartan and fexofenadine) to $30 \mathrm{ml} / \mathrm{min} / \mathrm{kg}$ (for pravastatin). Hepatic clearance was the major elimination mechanism for the drugs investigated, as $C L_{R}$ contributed $>20 \%$ for only three drugs (rosuvastatin, fexofenadine, and pravastatin). Hence hepatic clearance values indicated that four drugs had low hepatic extraction ratios (valsartan, repaglinide, fexofenadine, and telmisartan with hepatic clearances $<12 \mathrm{ml} / \mathrm{min} / \mathrm{kg}$; average hepatic blood flow $43.6 \mathrm{ml} / \mathrm{min} / \mathrm{kg}$ ), whereas the remaining drugs were medium hepatic clearance (with values between 12 and $32 \mathrm{ml} / \mathrm{min} / \mathrm{kg}$ ). The relationship between cynomolgus monkey and human hepatic clearance in vivo is shown in Fig. 6A, and with the exceptions of pravastatin and telmisartan, there was a good interspecies agreement over two orders of magnitude showing little bias (gmfe 2.6).

Figures $6 \mathrm{~B}$ and $7 \mathrm{~A}$ show the predictions of both cynomolgus monkey and human in vivo intrinsic clearance from in vitro parameters, respectively. Direct extrapolation of cynomolgus monkey hepatocyte data (Fig. 6B) resulted in a good agreement with observed cynomolgus monkey $\mathrm{CL}_{\text {int,h }}$ (gmfe 2.7 , rmse 899 ), with pravastatin as the most pronounced outlier ( $>2$-fold bias). In comparison, the corresponding prediction of human in vivo clearance from human hepatocytes (Fig. 7A), although showing similar rank order to the cynomolgus monkey data, has less precision (Table 4) and more bias (gmfe 3.8). Application of these respective species gmfe values to the 

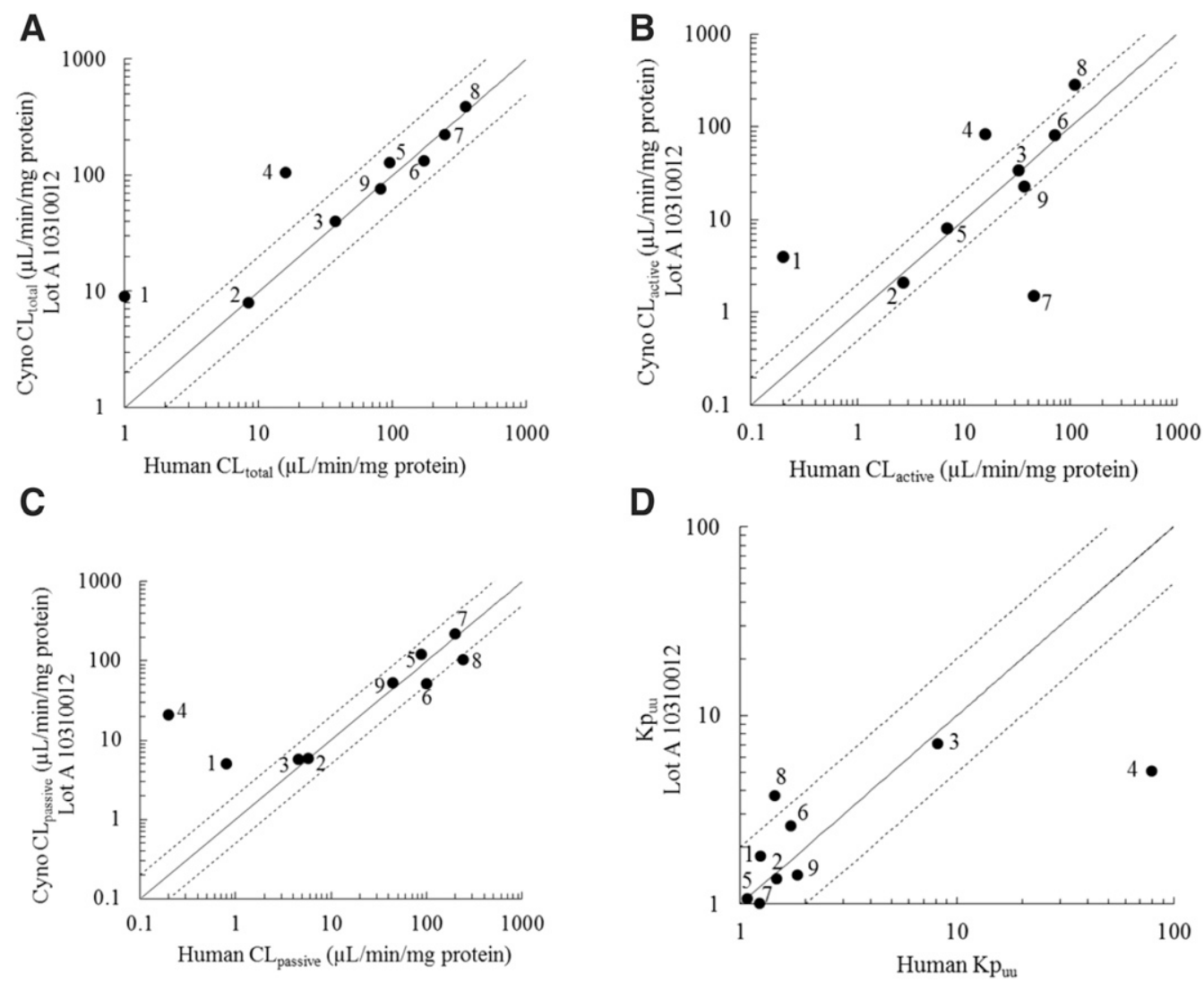

Fig. 4. Comparison of the kinetic parameters (A-C) and hepatocyte to medium partition coefficient for unbound drug (Kp $\mathrm{pu}$ ) (D) of nine OATP substrates obtained between cynomolgus monkey (lot A 10310012) and human hepatocytes (HH1025). $\mathrm{CL}_{\text {total }}, \mathrm{CL}_{\text {active, }}$, and $\mathrm{CL}_{\text {passive }}$ are total, active, and passive uptake clearance, respectively. Solid and dashed lines represent the line of unity and the 2-fold under-/overprediction boundaries, respectively. Numbers shown relate to particular drugs: 1, pravastatin; 2 , fexofenadine; 3 , rosuvastatin; 4, valsartan; 5 , repaglinide; 6 , pitavastatin; 7, cerivastatin; 8 , telmisartan; 9, bosentan.

in vitro parameters to improve in vivo clearance predictions is shown in Supplemental Fig. 5.

The potential of using a cross-species ESF to optimize human prediction was explored in two ways. First, the use of $\mathrm{ESF}_{\mathrm{av}}$ (gmfe from the cynomolgus monkey relationship between in vivo clearance and in vitropredicted clearance for the nine drugs investigated) is shown in Fig. 7B. This reduced the prediction bias for human prediction and noticeably improved the precision for this set of drugs (Table 4). Consideration of each drug individually shows that prediction was improved for six drugs (repaglinide, cerivastatin, pravastatin, bosentan, telmisartan, and valsartan), rosuvastatin was unaffected (its prediction being within 2-fold without the use of additional scaling factor), and prediction was less accurate for fexofenadine and pitavastatin, as clearly shown in the residual plots in Fig. 7, D and E. Use of individual drug empirical scaling factors for each specific drug $\left(\mathrm{ESF}_{\mathrm{sd}}\right.$ listed in Table 5) also shows an improved overall prediction and mixed success with individual drugs (Fig. 7, C and F; Table 4). Whereas pravastatin, cerivastatin, and bosentan were very well predicted by this approach, prediction accuracy of telmisartan was
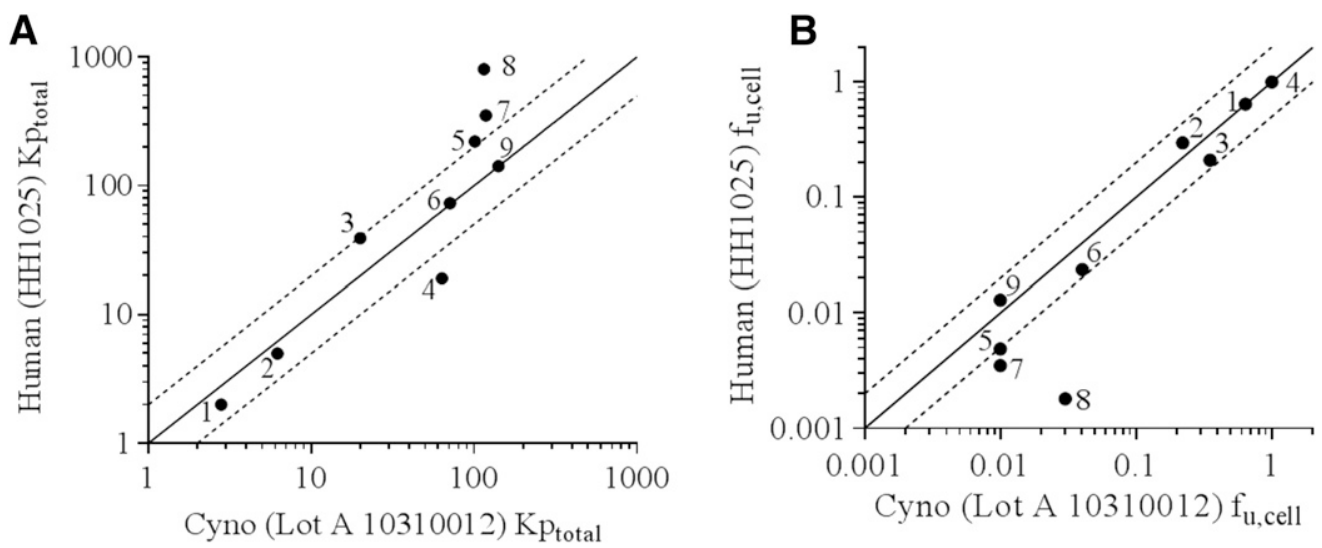

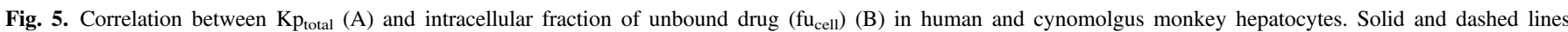

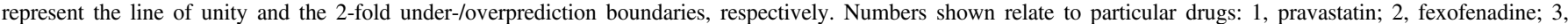
rosuvastatin; 4 , valsartan; 5 , repaglinide; 6 , pitavastatin; 7 , cerivastatin; 8 , telmisartan; 9 , bosentan. 
TABLE 3

In vivo hepatic clearance values, $\mathrm{R}_{\mathrm{b}}$ values, and protein binding for nine OATP substrates

In vivo hepatic clearance values $\left(C L_{\text {int, } h}\right)$ were calculated from in vivo $C L_{h}$ after intravenous dosing to cynomolgus monkeys. Blood-to-plasma partitioning $\left(R_{b}\right)$ in cynomolgus monkeys was assumed to be equal to reported $R_{b}$ values in humans. Protein binding was determined in vitro using membrane dialysis.

\begin{tabular}{|c|c|c|c|c|c|c|c|}
\hline \multirow{2}{*}{ Species } & $\mathrm{CL}_{\text {total }}$ & $\mathrm{CL}_{\mathrm{R}}$ & $\mathrm{CL}_{\mathrm{h}}$ & $\mathrm{CL}_{\mathrm{int}, \mathrm{h}}$ & $\mathrm{R}_{\mathrm{b}}$ & $\mathrm{f}_{\mathrm{u}}$ & \multirow{2}{*}{ References } \\
\hline & \multicolumn{4}{|c|}{$\mathrm{ml} / \mathrm{min} / \mathrm{kg}$} & & & \\
\hline \multicolumn{8}{|l|}{ Bosentan } \\
\hline Cynomolgus & $17.9 \pm 3.1$ & $\mathrm{n} / \mathrm{d}$ & 17.9 & 776 & 0.66 & 0.061 & \\
\hline Human & 2.1 & $\mathrm{n} / \mathrm{d}$ & 2.1 & 468 & & 0.053 & Weber et al. (1996, 1999), Jones et al. (2012) \\
\hline \multicolumn{8}{|l|}{ Cerivastatin } \\
\hline Cynomolgus & $19 \pm 3.6$ & $\mathrm{n} / \mathrm{d}$ & 19 & 3181 & 0.76 & 0.014 & \\
\hline Human & 2.9 & $\mathrm{n} / \mathrm{d}$ & 2.9 & 1778 & & 0.002 & Muck et al. (1997), Jones et al. (2012) \\
\hline \multicolumn{8}{|l|}{ Fexofenadine } \\
\hline Cynomolgus & $6.5 \pm 1.7$ & 1.7 & 4.8 & 19 & 0.55 & 0.31 & \\
\hline Human & 3.1 & 1.2 & 1.9 & 13 & & 0.18 & Lappin et al. (2010), Watanabe et al. (2011) \\
\hline \multicolumn{8}{|l|}{ Pitavastatin } \\
\hline Cynomolgus & $10.9 \pm 2.4$ & 0.1 & 10.8 & 723 & 0.58 & 0.026 & \\
\hline Human & 5.7 & $\mathrm{n} / \mathrm{d}$ & 5.7 & 434 & & 0.025 & Watanabe et al. (2010) \\
\hline \multicolumn{8}{|l|}{ Pravastatin } \\
\hline Cynomolgus & $30 \pm 4.0$ & 6.9 & 23.1 & 644 & 0.56 & 0.65 & \\
\hline Human & 14 & 6.6 & 7.4 & 48 & & 0.43 & Singhvi et al. (1990), Jones et al. (2012), Poulin et al. (2012) \\
\hline \multicolumn{8}{|l|}{ Repaglinide } \\
\hline Cynomolgus & $6.9 \pm 0.7$ & $\mathrm{n} / \mathrm{d}$ & 6.9 & 771 & 0.62 & 0.012 & \\
\hline Human & 7.8 & $\mathrm{n} / \mathrm{d}$ & 7.8 & 1326 & & 0.015 & van Heiningen et al. (1999), Plum et al. (2000), Obach et al. (2008) \\
\hline \multicolumn{8}{|r|}{ (1) } \\
\hline Cynomolgus & $23.7 \pm 1.8$ & 4.3 & 19.4 & 305 & 0.69 & 0.18 & \\
\hline Human & 10.5 & 2.9 & 7.6 & 172 & & 0.09 & Martin et al. (2003), Jones et al. (2012) \\
\hline \multicolumn{8}{|l|}{ Telmisartan } \\
\hline Cynomolgus & $9 \pm 2.5$ & $\mathrm{n} / \mathrm{d}$ & 9 & 490 & 0.78 & 0.025 & \\
\hline Human & 12 & $\mathrm{n} / \mathrm{d}$ & 12 & 9657 & & 0.005 & Stangier et al. (2000), Yoshida et al. (2012), Shitara et al. (2013) \\
\hline \multicolumn{8}{|r|}{ (2) } \\
\hline Cynomolgus & $6.5 \pm 0.6$ & 0.6 & 5.9 & 560 & 0.55 & 0.014 & \\
\hline Human & 0.49 & 0.14 & 0.35 & 361 & & 0.001 & Flesch et al. (1997), Watanabe et al. (2011), Jones et al. (2012) \\
\hline
\end{tabular}

$\mathrm{n} / \mathrm{d}$, not detectable.

decreased, and the remaining five drugs showed little difference. An analogous presentation of the improved human prediction using the previously reported values from three other human donors from applying the cross-species ESFs is shown in Supplemental Fig. 6.

\section{Discussion}

In the current study, the hepatic uptake of nine OATP substrates (rosuvastatin, pravastatin, repaglinide, fexofenadine, cerivastatin, telmisartan, pitavastatin, bosentan, and valsartan), representing classes $1 \mathrm{~B}$ and $3 \mathrm{~B}$ in the extended clearance classification system, was investigated in cynomolgus monkeys both in vitro, using hepatocytes, and in vivo. Analogous in vitro studies were carried out in human hepatocytes; together with literature collated clinical studies, these data allow a detailed species comparison and assessment of the cynomolgus monkey as a preclinical model for prediction of OATP-mediated hepatic clearance. Previous studies using cynomolgus monkey hepatocytes have investigated $\mathrm{CL}_{\text {uptake }}$ of one or two drugs (pitavastatin,
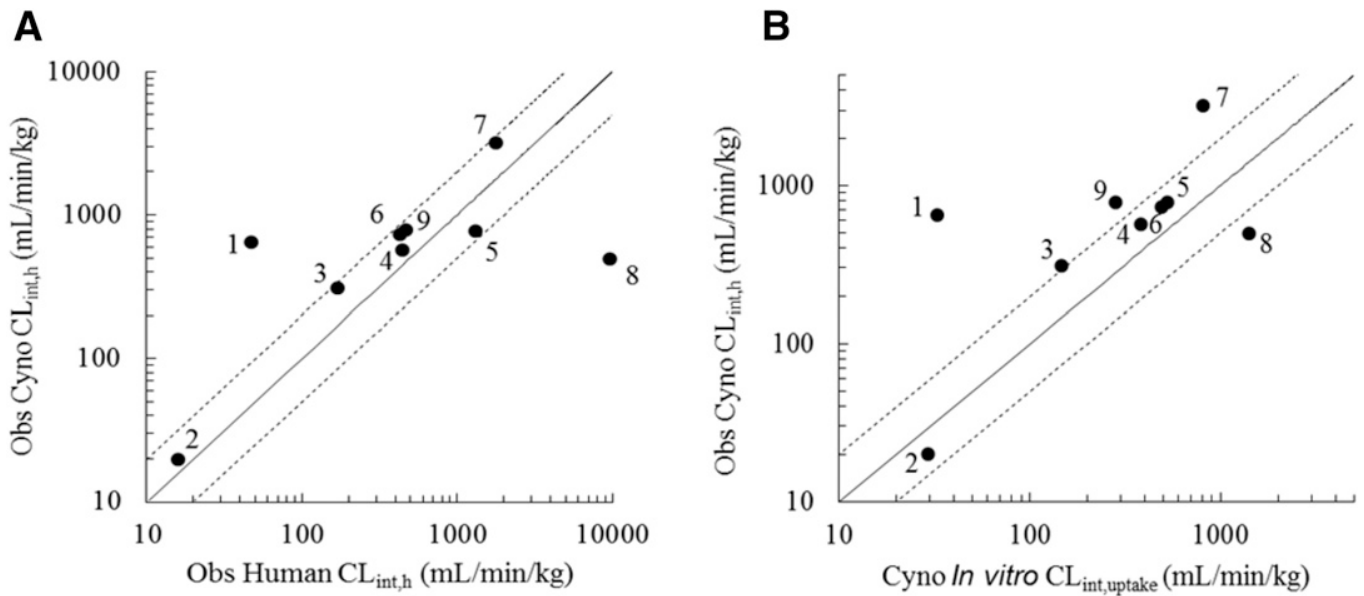

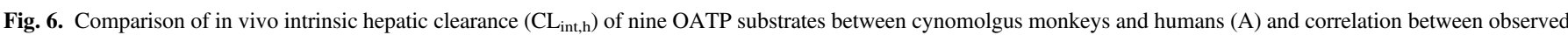

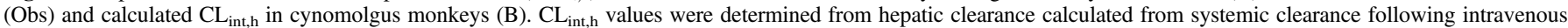

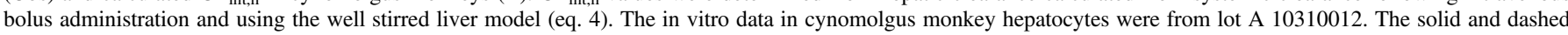

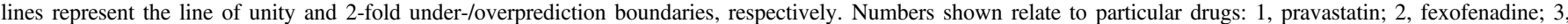
rosuvastatin; 4, valsartan; 5 , repaglinide; 6 , pitavastatin; 7 , cerivastatin; 8 , telmisartan; 9, bosentan. 

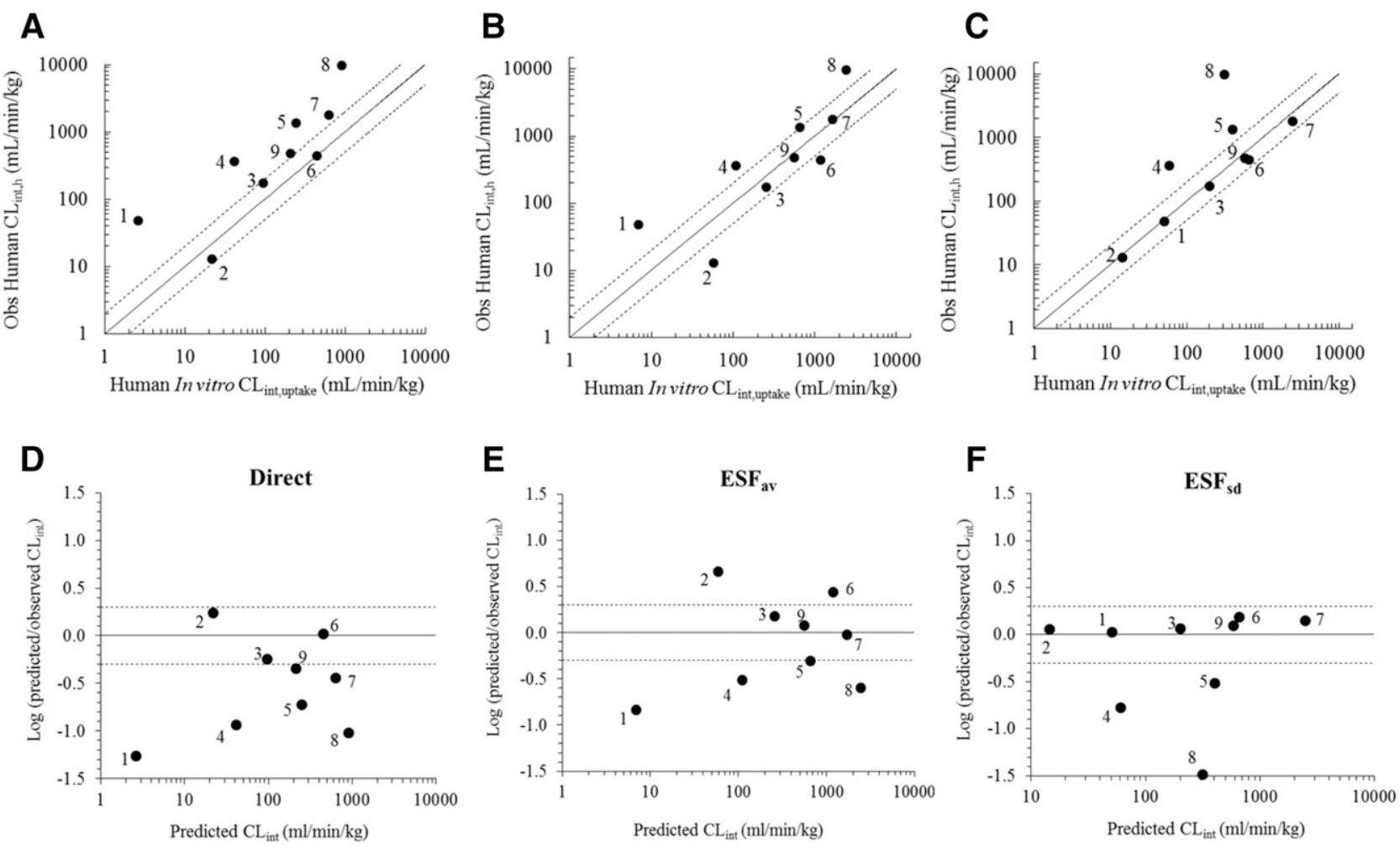

Fig. 7. Correlation between observed (Obs) and calculated in vivo intrinsic hepatic clearance values $\left(\mathrm{CL}_{\mathrm{int}, \mathrm{h}}\right.$; milliliters per minute per kilogram) in humans $(\mathrm{A}-\mathrm{C})$ and the corresponding residual plots for these predictions (D-F). Direct use of in vitro parameters (A and D) and use of empirical scaling factors (B, C, E, and F) for human prediction obtained from using either the average of all cynomolgus monkey drug clearances $\left(\mathrm{ESF}_{\mathrm{av}}\right)$ or individual specific drug clearances $\left(\mathrm{ESF}_{\mathrm{sd}}\right)$, respectively. The solid and dashed lines represent the line of unity and 2-fold under-/overprediction boundaries, respectively. Numbers shown relate to particular drugs: 1 , pravastatin; 2 , fexofenadine; 3 , rosuvastatin; 4 , valsartan; 5 , repaglinide; 6 , pitavastatin; 7 , cerivastatin; 8 , telmisartan; 9 , bosentan.

rosuvastatin, bosentan) in isolation with either no or limited application to predict in vivo clearance (Shen et al., 2013; Morse et al., 2017; Thakare et al., 2017), but for these drugs, there is a good agreement with current findings.

We used two donor sources for cynomolgus monkey hepatocytes, and to ensure representative coverage, one lot represents a pool of 20 livers (lot B). Hepatic disposition of the drug set in cynomolgus monkey hepatocytes was compared with parameters from the human donor under identical experimental conditions. We have previously reported human data on seven of these drugs in our own laboratory, and the rank order of

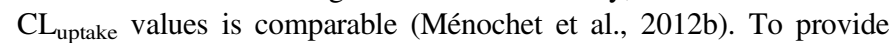
confidence in the human data derived in this study, we also used the mean of these donors (also shown in Fig. 1) for subsequent analyses. Total uptake clearance values in plated monkey hepatocytes ranged over 50-fold and showed a comparable rank order to in vitro data obtained under the same experimental conditions in plated human hepatocytes

TABLE 4

Statistical data comparing the accuracy and precision of the approaches used to predict human $\mathrm{CL}_{\mathrm{int}, \mathrm{h}}$

Human donor HH1025 hepatocytes were used.

\begin{tabular}{lccc}
\hline & \multicolumn{3}{c}{ Methods } \\
\cline { 2 - 4 } & Direct & ESF $_{\mathrm{av}}$ & ESF $_{\mathrm{sd}}$ \\
\hline gmfe & $3.8(3.5)^{a}$ & $2.5(2.3)^{a}$ & $2.4(4.4)^{a}$ \\
rmse & 2963 & 2430 & 3140 \\
$\%$ within 2-fold error & $33(43)^{a}$ & $33(57)^{a}$ & $67(57)^{a}$ \\
\hline
\end{tabular}

${ }^{a}$ Corresponding metrics when published human donor hepatocyte pool (Ménochet et al., 2012b) was used. (150-fold range). This difference arises from the pravastatin values, and a similar species difference is apparent in the in vivo data. Telmisartan also shows a similar species difference (albeit in the opposite direction) in vivo, but this trend is not evident in hepatocytes.

This tendency for similar rank order for the nine drugs is apparent with all clearances determined in vitro, and there is a good agreement in the relative contribution of active transport to total uptake between cynomolgus and human data (Table 1). In cynomolgus hepatocytes, there is a 7-fold range observed in $\mathrm{Kp}_{\mathrm{uu}}$ values (Fig. 1); however, the range is wider for human hepatocytes due to the passive contribution for valsartan. For both species, the $\mathrm{Kp}_{\mathrm{uu}}$ values are relatively low; rosuvastatin and valsartan were $>5$, whereas the remaining drugs were between 1 and 2 in human and 1 and 4 in cynomolgus monkey hepatocytes. This raises the question of whether the inhibition properties of rifamycin SV are adequate for passive clearance determination, and

TABLE 5

Drug-specific empirical scaling factors obtained in cynomolgus monkey hepatocytes and used to estimate $\mathrm{CL}_{\text {int,uptake }}$ in human hepatocytes

\begin{tabular}{lc}
\hline Compounds & ESF \\
\hline Rosuvastatin & 2.07 \\
Pitavastatin & 1.47 \\
Valsartan & 1.46 \\
Repaglinide & 1.63 \\
Fexofenadine & 0.67 \\
Pravastatin & 19.5 \\
Telmisartan & 0.34 \\
Bosentan & 2.76 \\
Cerivastatin & 3.89 \\
\hline
\end{tabular}


other approaches ( $\mathrm{Li}$ et al., 2014; Bi et al., 2017) may prove to be more appropriate in the future. As the rank order of $\mathrm{CL}_{\text {active }}$ is, in general, in good agreement, the interspecies differences in $\mathrm{Kp}_{\mathrm{uu}}$ cannot be explained solely by protein expression levels of OATP/Oatp isoforms in the liver, and the interspecies difference in intrinsic transport capacities also has to be considered. Recently in vivo $\mathrm{Kp}_{\mathrm{uu}}$ was reported for rosuvastatin, and due to the magnitude of this parameter $(>200)$, the authors were critical of in vitro determination (Morse et al., 2017). However, adequate modeling of in vivo experimentation (to achieve steady state) and simultaneous consideration of all processes to obtain $\mathrm{Kp}_{\mathrm{uu}}$ is problematic, and such values cannot be taken as the gold standard. There has been much attention recently on the most appropriate approach to obtain $\mathrm{Kp}_{\mathrm{uu}}$ (Riccardi et al., 2017; Riede et al., 2017; Yoshikado et al., 2017), and a consensus has yet to be reached.

The present findings also confirm the value of predicting the $\mathrm{CL}_{\text {passive }}$ term (for acidic drugs at least) from $\log \mathrm{D}_{7.4}$ previously documented in rats (Yabe et al., 2011; Ménochet et al., 2012a), and given the experimental issues in the actual experimental determination of this clearance term ( $\mathrm{Li}$ et al., 2014; Bi et al., 2017), this supplemental approach has merit. A $>500$-fold range in $\mathrm{CL}_{\text {passive }}$ was observed in both species with the same extreme values. An exception to this trend was valsartan in the cynomolgus monkey, although some clarity to this anomaly from the log $\mathrm{D}_{7.4}$ relationship illustrates the utility of correlation. For four drugs (pitavastatin, rosuvastatin, telmisartan, and valsartan), active uptake was responsible for $>60 \%$ of total uptake, and two (cerivastatin and repaglinide) were $<10 \%$; fexofenadine, pravastatin, and bosentan were intermediate values. Although the contribution of the active transport component is less than anticipated, all the data reported in both species are consistent.

In addition, the extent of intracellular binding between species appears to be very comparable. Determining the extent of intracellular binding of drug in hepatocytes has important implications in elucidating both pharmacokinetic and pharmacodynamic processes, including prediction of drug-drug interaction risk (Zamek-Gliszczynski et al., 2013; Morse et al., 2015). Several experimental methods and in silico approaches have been proposed to estimate intracellular drug concentration (Chu et al., 2013b). The reasonable species agreement in $\mathrm{Kp}_{\text {total }}$ highlights the relative importance of tissue binding for these compounds. The $\log \mathrm{D}_{7.4}$ relationships with $\mathrm{fu}_{\text {cell }}$ are striking and are consistent with previous studies in both suspended and plated rat hepatocytes (Yabe et al., 2011; Ménochet et al., 2012a). Calculation of hepatic fu $\mathrm{u}_{\text {cell }}$ from the correlation with $\log \mathrm{D}_{7.4}$ can provide useful initial estimates of $\mathrm{fu}_{\mathrm{cell}}$ for implementation in the physiologically based pharmacokinetic models, in particular in the cases when other data are lacking or equivocal.

Four of the nine compounds selected for study undergo metabolism in human liver and probably also in cynomolgus monkey, and the question regarding impact on uptake parameters is pertinent. We used ABT as an inhibitor of cytochrome P450 metabolism, but as two drugs are known substrates for glucuronosyltransferase, additional considerations are necessary. As clearance was calculated from initial rates (over 2 or 5 minutes), the impact of any losses due to UGT metabolism was minimal, as glucuronidation of repaglinide and telmisartan was comparatively slow under those conditions. $\mathrm{Kp}_{\text {total }}$ was determined over a longer time when metabolism was more appreciable; however, as an equilibrium was reached in all cases, this was not a confounding issue.

It can be concluded that both in vitro and in vivo intrinsic clearances in both species appeared generally well correlated both within and cross species. The range of clearance values observed in cynomolgus monkeys following an intravenous infusion in a cassette dosing regimen is consistent with previous studies (Chu et al., 2015; Thakare et al., 2017). Direct extrapolation of cynomolgus monkey hepatocyte resulted in good concordance with in vivo $\mathrm{CL}_{\mathrm{int}, \mathrm{h}}$ : 2.7 bias on average, and five of the nine drugs within 2-fold range of in vivo values.
Several approaches for human in vivo prediction were explored: direct scaling of human hepatocytes with and without ESF and empirical cross-species scaling using cynomolgus monkey data by either $\mathrm{ESF}_{\mathrm{av}}$ or $\mathrm{ESF}_{\mathrm{sd}}$. Direct scaling for humans indicated less precision and more bias than for cynomolgus monkeys (Table 4). The application of empirical scaling factors from monkey studies $\left(\mathrm{ESF}_{\mathrm{av}}\right.$ or $\left.\mathrm{ESF}_{\mathrm{sd}}\right)$ did improve human prediction, reducing the overall prediction bias and noticeably improving the precision for this set of drugs (Table 4). When considering the improvement in prediction for each drug individually, there was mixed success with both approaches. Consideration of the drugs where underprediction is clearly evident serves to illustrate this situation. Prediction of pravastatin, the most problematic of the drugs studied, is improved by both approaches but particularly by $\mathrm{ESF}_{\mathrm{sd}}$. Fexofenadine and telmisartan are only improved by one approach (the former by $\mathrm{ESF}_{\mathrm{sd}}$ and the latter by $\mathrm{ESF}_{\mathrm{av}}$ ). Repaglinide and valsartan are similarly improved by both approaches. The remaining four drugs (rosuvastatin, cerivastatin, pitavastatin, and bosentan) show marginal changes from either approach. The nine drugs investigated can be assigned to class $1 \mathrm{~B}$ or 3B of the extended clearance classification system (Varma et al., 2015), the distinction being permeability. In the current data, no separation was apparent between the compounds in each class, highlighting that uptake dominates hepatic clearance in all cases.

The use of $\mathrm{ESF}_{\mathrm{sd}}$ was previously applied for human metabolic clearance prediction using rat-derived factors (Naritomi et al., 2001; Ito and Houston, 2005). If underprediction were in some way linked to specific chemical properties of particular drugs, then this approach would be valuable. However, this approach was thought not to have a broad application for human metabolic clearance prediction due to the lack of any strong correlation between the extent of underprediction from rat and human in vitro data reported recently (Wood et al., 2017). Further studies with transporter-mediated drugs are required to establish the broad applicability of the $\mathrm{ESF}_{\mathrm{sd}}$ approach. From the current studies shown in Fig. 7, C and F, it may be concluded that the $\mathrm{ESF}_{\mathrm{sd}}$ approach is most successful in optimizing human prediction if the number of drugs within the 2-fold range is the deciding criterion. However, by extending the analysis to include other donor livers (Supplemental Fig. 6), the advantage for $\mathrm{ESF}_{\mathrm{sd}}$ over $\mathrm{ESF}_{\mathrm{av}}$ is not confirmed.

The future use of $\mathrm{ESF}_{\mathrm{av}}$ looks promising as a metric to estimate the relative functional activity of isolated hepatocellular systems and hence minimize the in vitro-in vivo offset for human clearance prediction. Herewith, we report minor species differences between cynomolgus monkey and human hepatocyte in vitro uptake data for nine OATP substrates, which is consistent with genomic and proteomic studies (Ebeling et al., 2011; Shen et al., 2013). Since total in vitro uptake data are predictive of the observed in vivo data in cynomolgus monkeys in an analogous way to the human data, $\mathrm{ESF}_{\mathrm{av}}$ provides an independent measure of the potential shortcomings of the isolated hepatocyte system to refine human clearance prediction. The ability to supplement a physiologic scaling factor, which is a multiplier for total hepatic capacity whether based on hepatocellularity (Wood et al., 2017) or proteomic measurements (Ishida et al., 2018), with a measure of functional activity increases confidence for the prospective use of human hepatocytes for in vivo prediction of hepatic transporter-mediated clearance.

In summary, these investigations confirm the utility of the cynomolgus monkey as a valuable preclinical model for the investigation of hepatic uptake of OATP substrates. Both sets of in vitro data predict in vivo clearance well; the most successful human predictions were obtained using cross-species ESFs. A recent drug-drug interaction study involving rifampicin inhibition of pitavastatin and rosuvastatin active uptake demonstrated quantitative translation of in vitro-derived OATP1B $\mathrm{IC}_{50}$ to predict DDIs using cynomolgus monkey as a preclinical model (Ufuk et al., 2018) supports this claim. 


\section{Acknowledgments}

We thank Sue Murby, Dr. David Hallifax, and Jessica Sima for valuable assistance with liquid chromatography-tandem mass spectrometry analysis. Sangwoo Ryu and Keith Riccardi (Pfizer Inc.) are acknowledged for conducting plasma protein binding measurements.

\section{Authorship Contributions}

Participated in research design: De Bruyn, Ufuk, Cantrill, Tremaine, Varma, Galetin, Houston.

Conducted experiments: De Bruyn, Ufuk, Cantrill, Kosa, Bi, Niosi, Modi.

Performed data analysis: De Bruyn, Ufuk, Cantrill, Kosa.

Wrote or contributed to the writing of the manuscript: De Bruyn, Ufuk, Cantrill, Kosa, Bi, Niosi, Modi, Rodrigues, Tremaine, Varma, Galetin, Houston.

\section{References}

Akabane T, Tabata K, Kadono K, Sakuda S, Terashita S, and Teramura T (2010) A comparison of pharmacokinetics between humans and monkeys. Drug Metab Dispos 38 308-316.

Bi YA, Scialis RJ, Lazzaro S, Mathialagan S, Kimoto E, Keefer J, Zhang H, Vildhede AM, Costales C, Rodrigues AD, et al. (2017) Reliable rate measurements for active and passive hepatic uptake using plated human hepatocytes. AAPS J 19:787-796.

Brouwer KL, Keppler D, Hoffmaster KA, Bow DA, Cheng Y, Lai Y, Palm JE, Stieger B, and Evers R; International Transporter Consortium (2013) In vitro methods to support transporter evaluation in drug discovery and development. Clin Pharmacol Ther 94:95-112.

Chu X, Bleasby K, and Evers R (2013a) Species differences in drug transporters and implications for translating preclinical findings to humans. Expert Opin Drug Metab Toxicol 9:237-252.

Chu X, Korzekwa K, Elsby R, Fenner K, Galetin A, Lai Y, Matsson P, Moss A, Nagar S, Rosania GR, et al.; International Transporter Consortium (2013b) Intracellular drug concentrations and transporters: measurement, modeling, and implications for the liver. Clin Pharmacol Ther 94:126-141.

Chu X, Shih SJ, Shaw R, Hentze H, Chan GH, Owens K, Wang S, Cai X, Newton D, Castro-Perez J, et al. (2015) Evaluation of cynomolgus monkeys for the identification of endogenous biomarkers for hepatic transporter inhibition and as a translatable model to predict pharmacokinetic interactions with statins in humans. Drug Metab Dispos 43:851-863.

Davies B and Morris T (1993) Physiological parameters in laboratory animals and humans. Pharm Res 10:1093-1095.

Ebeling M, Küng E, See A, Broger C, Steiner G, Berrera M, Heckel T, Iniguez L, Albert T, Schmucki R, et al. (2011) Genome-based analysis of the nonhuman primate Macaca fascicularis as a model for drug safety assessment. Genome Res 21:1746-1756.

Feng B, Varma MV, Costales C, Zhang H, and Tremaine L (2014) In vitro and in vivo approaches to characterize transporter-mediated disposition in drug discovery. Expert Opin Drug Discov 9 873-890.

Flesch G, Müller P, and Lloyd P (1997) Absolute bioavailability and pharmacokinetics of valsartan, an angiotensin II receptor antagonist, in man. Eur J Clin Pharmacol 52:115-120.

Galetin A, Zhao P, and Huang S-M (2017) Physiologically based pharmacokinetic modeling of drug transporters to facilitate individualized dose prediction. J Pharm Sci 106:2204-2208.

Gertz M, Cartwright CM, Hobbs MJ, Kenworthy KE, Rowland M, Houston JB, and Galetin A (2013) Cyclosporine inhibition of hepatic and intestinal CYP3A4, uptake and efflux transporters: application of PBPK modeling in the assessment of drug-drug interaction potential. Pharm Res 30:761-780.

Gertz M, Harrison A, Houston JB, and Galetin A (2010) Prediction of human intestinal first-pass metabolism of 25 CYP3A substrates from in vitro clearance and permeability data. Drug Metab Dispos 38:1147-1158.

Gertz M, Tsamandouras N, Säll C, Houston JB, and Galetin A (2014) Reduced physiologicallybased pharmacokinetic model of repaglinide: impact of OATP1B1 and CYP2C8 genotype and source of in vitro data on the prediction of drug-drug interaction risk. Pharm Res 31.2367-2382.

Giacomini KM, Balimane PV, Cho SK, Eadon M, Edeki T, Hillgren KM, Huang SM, Sugiyama Y, Weitz D, Wen Y, et al.; International Transporter Consortium (2013) International Transporter Consortium commentary on clinically important transporter polymorphisms. Clin Pharmacol Ther 94:23-26.

Giacomini KM, Huang SM, Tweedie DJ, Benet LZ, Brouwer KL, Chu X, Dahlin A, Evers R, Fischer V, Hillgren KM, et al.; International Transporter Consortium (2010) Membrane transporters in drug development. Nat Rev Drug Discov 9:215-236.

Ishida K, Ullah M, Tóth B, Juhasz V, and Unadkat JD (2018) Successful prediction of in vivo hepatobiliary clearances and hepatic concentrations of rosuvastatin using sandwich-cultured rat hepatocytes, transporter-expressing cell lines, and quantitative proteomics. Drug Metab Dispos 46:66-74

Ito K and Houston JB (2005) Prediction of human drug clearance from in vitro and preclinical data using physiologically based and empirical approaches. Pharm Res 22:103-112.

Iwasaki K and Uno Y (2009) Cynomolgus monkey CYPs: a comparison with human CYPs. Xenobiotica 39:578-581.

Jones HM, Barton HA, Lai Y, Bi YA, Kimoto E, Kempshall S, Tate SC, El-Kattan A, Houston JB Galetin A, et al. (2012) Mechanistic pharmacokinetic modeling for the prediction of transportermediated disposition in humans from sandwich culture human hepatocyte data. Drug Metab Dispos 40:1007-1017.

Jones HM, Chen Y, Gibson C, Heimbach T, Parrott N, Peters SA, Snoeys J, Upreti VV, Zheng M, and Hall SD (2015) Physiologically based pharmacokinetic modeling in drug discovery and development: a pharmaceutical industry perspective. Clin Pharmacol Ther 97:247-262.

Kimoto E, Bi YA, Kosa RE, Tremaine LM, and Varma MVS (2017) Hepatobiliary clearance prediction: species scaling from monkey, dog, and rat, and in vitro-in vivo extrapolation of sandwich-cultured human hepatocytes using 17 drugs. J Pharm Sci 106:2795-2804.

Kimoto E, Walsky R, Zhang H, Bi YA, Whalen KM, Yang YS, Linder C, Xiao Y, Iseki K, Fenner KS, et al. (2012) Differential modulation of cytochrome P450 activity and the effect of 1-aminobenzotriazole on hepatic transport in sandwich-cultured human hepatocytes. Drug Metab Dispos 40:407-411.
Lappin G, Shishikura Y, Jochemsen R, Weaver RJ, Gesson C, Houston B, Oosterhuis B, Bjerrum OJ, Rowland M, and Garner C (2010) Pharmacokinetics of fexofenadine: evaluation of a microdose and assessment of absolute oral bioavailability. Eur J Pharm Sci 40:125-131.

Li R, Bi YA, Lai Y, Sugano K, Steyn SJ, Trapa PE, and Di L (2014) Permeability comparison between hepatocyte and low efflux MDCKII cell monolayer. AAPS J 16:802-809.

Liu L and Unadkat JD (2013) Interaction between HIV protease inhibitors (PIs) and hepatic transporters in sandwich cultured human hepatocytes: implication for PI-based DDIs. Biopharm Drug Dispos 34:155-164.

Lu Y, Slizgi JR, Brouwer KR, Claire RL, Freeman KM, Pan M, Brock WJ, and Brouwer KL (2016) Hepatocellular disposition and transporter interactions with tolvaptan and metabolites in sandwich-cultured human hepatocytes. Drug Metab Dispos 44:867-870.

Martin PD, Warwick MJ, Dane AL, Brindley C, and Short T (2003) Absolute oral bioavailability of rosuvastatin in healthy white adult male volunteers. Clin Ther 25:2553-2563.

Ménochet K, Kenworthy KE, Houston JB, and Galetin A (2012a) Simultaneous assessment of uptake and metabolism in rat hepatocytes: a comprehensive mechanistic model. I Pharmacol Exp Ther 341:2-15.

Ménochet K, Kenworthy KE, Houston JB, and Galetin A (2012b) Use of mechanistic modeling to assess interindividual variability and interspecies differences in active uptake in human and rat hepatocytes. Drug Metab Dispos 40:1744-1756

Miyake M, Koga T, Kondo S, Yoda N, Emoto C, Mukai T, and Toguchi H (2017) Prediction of drug intestinal absorption in human using the Ussing chamber system: a comparison of intestinal tissues from animals and humans. Eur J Pharm Sci 96:373-380.

Morse BL, Cai H, MacGuire JG, Fox M, Zhang L, Zhang Y, Gu X, Shen H, Dierks EA, Su H, et al. (2015) Rosuvastatin liver partitioning in cynomolgus monkeys: measurement in vivo and prediction using in vitro monkey hepatocyte uptake. Drug Metab Dispos 43:1788-1794.

Morse BL, MacGuire JG, Marino AM, Zhao Y, Fox M, Zhang Y, Shen H, Griffith Humphreys W, Marathe P, and Lai Y (2017) Physiologically based pharmacokinetic modeling of transportermediated hepatic clearance and liver partitioning of OATP and OCT substrates in cynomolgus monkeys. AAPS J 19:1878-1889.

Mück W, Ritter W, Ochmann K, Unger S, Ahr G, Wingender W, and Kuhlmann J (1997) Absolute and relative bioavailability of the HMG-CoA reductase inhibitor cerivastatin. Int J Clin Pharmacol Ther 35:255-260.

Naritomi Y, Terashita S, Kimura S, Suzuki A, Kagayama A, and Sugiyama Y (2001) Prediction of human hepatic clearance from in vivo animal experiments and in vitro metabolic studies with liver microsomes from animals and humans. Drug Metab Dispos 29:1316-1324.

Nishimuta H, Sato K, Mizuki Y, Yabuki M, and Komuro S (2010) Prediction of the intestinal firstpass metabolism of CYP3A substrates in humans using cynomolgus monkeys. Drug Metab Dispos 38:1967-1975.

Obach RS, Lombardo F, and Waters NJ (2008) Trend analysis of a database of intravenous pharmacokinetic parameters in humans for 670 drug compounds. Drug Metab Dispos 36:1385-1405.

Pang KS and Rowland M (1977) Hepatic clearance of drugs. I. Theoretical considerations of a "well-stirred" model and a "parallel tube" model. Influence of hepatic blood flow, plasma and blood cell binding, and the hepatocellular enzymatic activity on hepatic drug clearance. I Pharmacokinet Biopharm 5:625-653.

Plum A, Müller LK, and Jansen JA (2000) The effects of selected drugs on the in vitro protein binding of repaglinide in human plasma. Methods Find Exp Clin Pharmacol 22:139-143.

Poulin P, Kenny JR, Hop CE, and Haddad S (2012) In vitro-in vivo extrapolation of clearance: modeling hepatic metabolic clearance of highly bound drugs and comparative assessment with existing calculation methods. J Pharm Sci 101:838-851.

Rawden HC, Carlile DJ, Tindall A, Hallifax D, Galetin A, Ito K, and Houston JB (2005) Microsomal prediction of in vivo clearance and associated interindividual variability of six benzodiazepines in humans. Xenobiotica 35:603-625.

Reinoso RF, Telfer BA, Brennan BS, and Rowland M (2001) Uptake of teicoplanin by isolated rat hepatocytes: comparison with in vivo hepatic distribution. Drug Metab Dispos 29:453-459.

Riccardi K, Lin J, Li Z, Niosi M, Ryu S, Hua W, Atkinson K, Kosa RE, Litchfield J, and Di L (2017) Novel method to predict in vivo liver-to-plasma $K_{\mathrm{puu}}$ for OATP substrates using suspension hepatocytes. Drug Metab Dispos 45.576-580.

Riede J, Camenisch G, Huwyler J, and Poller B (2017) Current in vitro methods to determine hepatic $\mathrm{Kp}_{\mathrm{uu}}$ : a comparison of their usefulness and limitations. J Pharm Sci 106:2805-2814.

Shen H, Su H, Liu T, Yao M, Mintier G, Li L, Fancher RM, Iyer R, Marathe P, Lai Y, et al. (2015) Evaluation of rosuvastatin as an organic anion transporting polypeptide (OATP) probe substrate: in vitro transport and in vivo disposition in cynomolgus monkeys. J Pharmacol Exp Ther 353 380-391.

Shen H, Yang Z, Mintier G, Han YH, Chen C, Balimane P, Jemal M, Zhao W, Zhang R, Kallipatti S, et al. (2013) Cynomolgus monkey as a potential model to assess drug interactions involving hepatic organic anion transporting polypeptides: in vitro, in vivo, and in vitro-to-in vivo extrapolation. J Pharmacol Exp Ther 344:673-685.

Shitara Y, Maeda K, Ikejiri K, Yoshida K, Horie T, and Sugiyama Y (2013) Clinical significance of organic anion transporting polypeptides (OATPs) in drug disposition: their roles in hepatic clearance and intestinal absorption. Biopharm Drug Dispos 34:45-78.

Singhvi SM, Pan HY, Morrison RA, and Willard DA (1990) Disposition of pravastatin sodium, a tissue-selective HMG-CoA reductase inhibitor, in healthy subjects. Br J Clin Pharmacol 29: 239-243.

Stangier J, Su CA, and Roth W (2000) Pharmacokinetics of orally and intravenously administered telmisartan in healthy young and elderly volunteers and in hypertensive patients. J Int Med Res 28:149-167.

Takahashi M, Washio T, Suzuki N, Igeta K, and Yamashita S (2009) The species differences of intestinal drug absorption and first-pass metabolism between cynomolgus monkeys and humans. J Pharm Sci 98:4343-4353.

Takahashi T, Ohtsuka T, Yoshikawa T, Tatekawa I, Uno Y, Utoh M, Yamazaki H, and Kume T (2013) Pitavastatin as an in vivo probe for studying hepatic organic anion transporting polypeptide-mediated drug-drug interactions in cynomolgus monkeys. Drug Metab Dispos 41 $1875-1882$.

Thakare R, Gao H, Kosa RE, Bi YA, Varma MVS, Cerny MA, Sharma R, Kuhn M, Huang B, Liu Y, et al. (2017) Leveraging of rifampicin-dosed cynomolgus monkeys to identify bile acid 3-O-sulfate conjugates as potential novel biomarkers for organic anion-transporting polypeptides. Drug Metab Dispos 45:721-733.

Ufuk A, Kosa RE, Gao H, Bi YA, Modi S, Gates D, Rodrigues AD, Tremaine LM, Varma MVS, Houston JB, et al. (2018) In vitro - in vivo extrapolation of OATP1B-mediated drug-drug interactions in cynomolgus monkey. J Pharmacol Exp Ther 365:688-699. 
van Heiningen PN, Hatorp V, Kramer Nielsen K, Hansen KT, van Lier JJ, De Merbel NC, Oosterhuis B, and Jonkman JH (1999) Absorption, metabolism and excretion of a single oral dose of (14)C-repaglinide during repaglinide multiple dosing. Eur J Clin Pharmacol 55 521-525.

Varma MV, El-Kattan AF, Feng B, Steyn SJ, Maurer TS, Scott DO, Rodrigues AD, and Tremaine LM (2017) Extended clearance classification system (ECCS) informed approach for evaluating investigational drugs as substrates of drug transporters. Clin Pharmacol Ther 102:33-36.

Varma MV, Steyn SJ, Allerton C, and El-Kattan AF (2015) Predicting clearance mechanism in drug discovery: Extended Clearance Classification System (ECCS). Pharm Res 32:3785-3802.

Wang L, Prasad B, Salphati L, Chu X, Gupta A, Hop CE, Evers R, and Unadkat JD (2015) Interspecies variability in expression of hepatobiliary transporters across human, dog, monkey, and rat as determined by quantitative proteomics. Drug Metab Dispos 43:367-374.

Watanabe M, Watanabe T, Yabuki M, and Tamai I (2015) Dehydroepiandrosterone sulfate, a useful endogenous probe for evaluation of drug-drug interaction on hepatic organic anion transporting polypeptide (OATP) in cynomolgus monkeys. Drug Metab Pharmacokinet 30 198-204.

Watanabe T, Kusuhara H, Maeda K, Kanamaru H, Saito Y, Hu Z, and Sugiyama Y (2010) Investigation of the rate-determining process in the hepatic elimination of HMG-CoA reductase inhibitors in rats and humans. Drug Metab Dispos 38:215-222.

Watanabe T, Kusuhara H, Watanabe T, Debori Y, Maeda K, Kondo T, Nakayama H, Horita S, Ogilvie BW, Parkinson A, et al. (2011) Prediction of the overall renal tubular secretion and hepatic clearance of anionic drugs and a renal drug-drug interaction involving organic anion transporter 3 in humans by in vitro uptake experiments. Drug Metab Dispos 39:1031-1038.

Weber C, Schmitt R, Birnboeck H, Hopfgartner G, Eggers H, Meyer J, van Marle S, Viischer HW, and Jonkman JH (1999) Multiple-dose pharmacokinetics, safety, and tolerability of bosentan, an endothelin receptor antagonist, in healthy male volunteers. J Clin Pharmacol 39:703-714.
Weber C, Schmitt R, Birnboeck H, Hopfgartner G, van Marle SP, Peeters PA, Jonkman JH, and Jones CR (1996) Pharmacokinetics and pharmacodynamics of the endothelin-receptor antagonist bosentan in healthy human subjects. Clin Pharmacol Ther 60:124-137.

Wood FL, Houston JB, and Hallifax D (2017) Clearance prediction methodology needs fundamenta improvement: trends common to rat and human hepatocytes/microsomes and implications for experimental methodology. Drug Metab Dispos 45:1178-1188.

Yabe Y, Galetin A, and Houston JB (2011) Kinetic characterization of rat hepatic uptake of 16 actively transported drugs. Drug Metab Dispos 39:1808-1814.

Yoshida K, Maeda K, and Sugiyama Y (2012) Transporter-mediated drug-drug interactions involving OATP substrates: predictions based on in vitro inhibition studies. Clin Pharmacol Ther 91:1053-1064.

Yoshikado T, Toshimoto K, Nakada T, Ikejiri K, Kusuhara H, Maeda K, and Sugiyama Y (2017) Comparison of methods for estimating unbound intracellular-to-medium concentration ratios in rat and human hepatocytes using statins. Drug Metab Dispos 45:779-789.

Zamek-Gliszczynski MJ, Lee CA, Poirier A, Bentz J, Chu X, Ellens H, Ishikawa T, Jamei M, Kalvass JC, Nagar S, et al.; International Transporter Consortium (2013) ITC recommendations for transporter kinetic parameter estimation and translational modeling of transport-mediated PK and DDIs in humans. Clin Pharmacol Ther 94:64-79.

Address correspondence to: Dr. J. Brian Houston, Centre for Applied Pharmacokinetic Research, Division of Pharmacy and Optometry, School of Medicine, Biology and Health Sciences, University of Manchester, Oxford Road, M13 9PT Manchester, UK. E-mail: brian.houston@manchester.ac.uk 